\title{
Asymmetric cell division of stem and progenitor cells during homeostasis and cancer
}

\author{
Sandra Gómez-López • Robin G. Lerner • \\ Claudia Petritsch
}

Received: 29 March 2013 / Revised: 21 May 2013 / Accepted: 24 May 2013 / Published online: 15 June 2013

(C) The Author(s) 2013. This article is published with open access at Springerlink.com

\begin{abstract}
Stem and progenitor cells are characterized by their ability to self-renew and produce differentiated progeny. A fine balance between these processes is achieved through controlled asymmetric divisions and is necessary to generate cellular diversity during development and to maintain adult tissue homeostasis. Disruption of this balance may result in premature depletion of the stem/progenitor cell pool, or abnormal growth. In many tissues, including the brain, dysregulated asymmetric divisions are associated with cancer. Whether there is a causal relationship between asymmetric cell division defects and cancer initiation is as yet not known. Here, we review the cellular and molecular mechanisms that regulate asymmetric cell divisions in the neural lineage and discuss the potential connections between this regulatory machinery and cancer.
\end{abstract}

Keywords Asymmetric cell division · Polarity $\cdot$ Neural stem cell · Oligodendrocyte precursor cell · Glioma . Tumor-propagating cell $\cdot$ Cancer stem cell

S. Gómez-López · R. G. Lerner · C. Petritsch $(\bowtie)$

Department of Neurological Surgery, University of California,

San Francisco, San Francisco, CA, USA

e-mail: claudia.petritsch@ucsf.edu

\section{Petritsch}

Brain Tumor Research Center, University of California, San Francisco, San Francisco, CA, USA

C. Petritsch

Helen Diller Comprehensive Cancer Center, University

of California, San Francisco, San Francisco, CA, USA

C. Petritsch

Eli and Edythe Broad Center of Regeneration Medicine and Stem Cell Research, University of California, San Francisco,

San Francisco, CA, USA

\section{Introduction}

Asymmetric cell division (ACD) is a fundamental process whereby the asymmetric inheritance of cellular components (e.g. proteins, RNAs) during mitosis defines distinct fates for each daughter cell. This evolutionarily conserved division mode is used by stem and progenitor cells in different tissues. In a typical outcome of an asymmetric division, the stem or progenitor cell generates a copy of itself, which retains self-renewal ability and differentiation potential, and one daughter that enters the path of differentiation. Thus, by balancing self-renewal with differentiation, asymmetric divisions maintain the stem and progenitor cell pool while allowing the generation of diverse functional cells.

Much of what we know about the regulation of ACD is gleaned from studies of the stem-like cells of the central nervous system of Drosophila, the neuroblasts (NBs). These studies in Drosophila have shown that disruption of ACD leads to abnormal proliferation and genomic instability, indicating that ACD may operate as a tumor suppressor mechanism during normal development [1]. Investigations of the mammalian central nervous system have more recently revealed that neural stem cells (NSCs) and oligodendrocyte precursor cells (OPCs) undergo ACD [2, 3]. Moreover, decreased ACD frequency has been found in cancers with a stem and progenitor foundation, such as leukemia [4], brain tumors [3], and mammary carcinomas [5]. Intriguingly, however, a subset of highly tumorigenic cancer cells with stem cell properties, the cancer stem cells (CSCs), retain their ability to divide asymmetrically in established brain tumors [6], suggesting that ACD may play an important role in tumor maintenance. We will therefore first describe how ACD is established in Drosophila NBs and subsequently discuss the extent to which these mechanisms appear to be conserved in the mammalian neural 
lineage. In the final part of this review, we will discuss the emerging roles of ACD regulators in controlling cellular features observed during the initiation and progression of human cancers.

\section{Asymmetric divisions of Drosophila melanogaster neuroblasts}

Drosophila NBs are the most thoroughly studied model system of ACD, where basic principles of polarity, spindle orientation, and cell-fate determination have been revealed [7]. Embryonic NBs undergo several rounds of asymmetric divisions, during which determinants of differentiating fate concentrate at the basal cell cortex before mitosis and segregate unequally during cytokinesis, to generate each time another NB and a more restricted progenitor called ganglion mother cell (GMC). At early stages of larval development, and after a period of quiescence, NBs re-enter the cell cycle and continue to divide asymmetrically to produce GMCs, either directly (type I NBs) or via intermediate progenitors (type II NBs) [8-10].

\section{Establishing polarity}

Embryonic NBs delaminate from a polarized neuroectoderm and inherit apically positioned Bazooka (Baz or Par3) protein. Baz serves as an apical polarity cue and during late interphase/early prophase, assembles a polarity complex [11]. Baz binds and activates the Rho GTPase family $\mathrm{Cdc} 42$ [12], which in turn recruits atypical protein kinase $\mathrm{C}$ (aPKC) and the aPKC inhibitory subunit Par6 [12, 13]. In prophase, the apical complex also binds to the adaptor protein Inscuteable (Insc) [14] and thereby initiates the assembly of a second complex consisting of partner of Insc (Pins)
[11] and the heterotrimeric $\mathrm{G}$ protein coupled subunits $\mathrm{G} \alpha \mathrm{i}$ and G $\beta \gamma$. Pins-dependent heterotrimer formation of Gai/ $\beta \gamma$ activates $G$ protein signaling in a transmembrane receptorindependent manner [15] and in the absence of nucleotide exchange [16].

In metaphase, the mitotic kinase Aurora A (AurA) phosphorylates Par6, which in conjunction with Baz/Cdc42 binding leads to aPKC activation [14, 17, 18]. Protein phosphatase $2 \mathrm{~A}(\mathrm{PP} 2 \mathrm{~A})$ restricts active aPKC to the apical cortex in larval NBs $[19,20]$ and dephosphorylates Baz and Par6 in embryonic NBs [17, 21]. Thus, NB polarity is established through the dynamic physical association of scaffold proteins, which coordinate GTPase, kinase, and phosphatase activities. The activation of $\mathrm{G}$ protein signaling through Pins occurs cell intrinsically and not only stabilizes apical polarity but also positions the nascent mitotic spindle along the apico-basal axis and determines its size asymmetry (Fig. 1).

Orienting the mitotic spindle

Proper apico-basal spindle positioning depends on a dynamic cross-talk between polarity and spindle-orientating complexes at the cortex with centrosomes and astral microtubules. Shortly after cytokinesis is completed, NBs prepare for the next round of division by localizing one centrosome to the vicinity of the apical pole. The apical centrosome forms astral microtubules and anchors in a Pins-dependent manner. After it duplicates, the mother centrosome moves away to the basal pole [22]. In actively cycling larval NBs, the apical centrosome provides polarity cues that precede those provided by the apical polarity complex and it functions as a spatial memory for proper spindle axis formation in subsequent rounds of divisions [22-24].

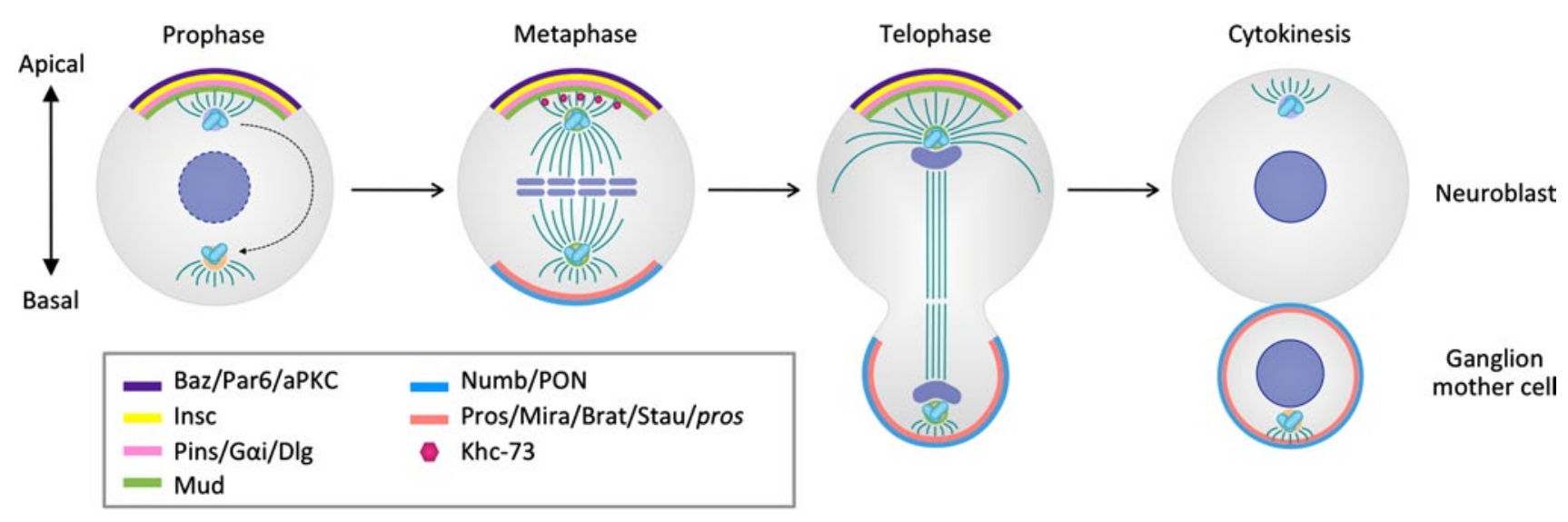

Fig. 1 Asymmetric division in Drosophila neuroblasts. Polarized localization of apical complexes is established during prophase. During metaphase and telophase, the spindle is anchored and orientated relative to the axis of apico-basal polarity. Cell-fate determinants are asymmetrically segregated into self-renewing neuroblasts or differentiating ganglion mother cells 
The coiled-coiled domain protein mushroom bodydefective (Mud) binds to the centrosome and links astral microtubules to the apical complex by interacting with Pins [25-27]. The microtubule-cortex contact is additionally controlled by the MAGUK Disc large (Dlg), which physically interacts with Pins at the cortex and with kinesin Khc73 at the microtubule plus ends [28, 29]. Pins/Mud interactions stabilize the mitotic spindle and Pins/Gai/Dlg/Khc-73 interactions establish a positive feedback loop, and thereby maintain apical cortical polarity as well as the correct spindle orientation.

The temporal coordination of spindle positioning is less well understood and it is known to require the Polo and AurA kinases [30-32]. Polo kinase is part of the spindle assembly checkpoint that ensures that microtubules are properly connected to kinetochores and that chromosomes segregate correctly. Polo therefore potentially links the temporal control of ACD with the global temporal control of mitosis and proper ploidy.

\section{Cell-fate decision control}

The Baz/Par6/aPKC complex directs the basal distribution of the cell-fate determinant Numb, an evolutionary conserved protein primarily known for its ability to inhibit the Notch signaling pathway, and the adaptor protein Miranda (Mira). This process depends on an intact actin cytoskeleton [33] and two myosin motors, MyoII and MyoVI, which operate downstream of the apical complex [34].

In interphase, aPKC and Par6 form a complex with the WD40 protein lethal giant larvae ( $\mathrm{Lgl})$. Mitotic phosphorylation of Par6 by AurA stimulates aPKC to phosphorylate $\mathrm{Lgl}$, which is then released from aPKC, allowing Baz to enter the Par complex [18, 35]. Assembly of Baz/ Par6/aPKC changes aPKC substrate specificity, allowing it to phosphorylate Numb and releasing it from the apical cortex $[18,36]$. Phosphorylated Numb then localizes to the basal side of the cell [36] assisted by the adaptor protein Partner of Numb (PON) [37], whose activity is largely dependent on its phosphorylation by Polo kinase [30]. Once in the GMC, Numb prevents self-renewal, predominantly by antagonizing Notch signaling [31].

Similar to Numb, Mira polarization has been proposed to occur as a consequence of direct aPKC phosphorylation $[18,38]$. However, in aurA mutant NBs, which display delocalized aPKC, Mira distribution is unaltered [31, 32], implying the existence of alternative mechanisms acting upstream of or in parallel to aPKC. Mira binds to and directs the asymmetric localization of distinct cell-fate determinants, including the transcriptional regulator Prospero (Pros) [39, 40], the double-stranded (ds) RNA-binding protein Staufen (Stau) [41, 42] and the NHL-domain protein Brain tumor (Brat) $[43,44]$. Stau binds to pros mRNA, through its 3' UTR, and localizes it to the GMC [45, 46], which itself does not transcribe the pros gene [46]. In the GMC, Prospero activates a neurogenic program [47, 48] and represses expression of genes associated with stem cell fate and cell-cycle progression [49]. Brat, on the other hand, promotes cell-cycle exit, represses NB fate, and inhibits cell growth [43, 44, 50], at least in part, by inhibiting the expression of the transcription factor $\mathrm{dMyc}$ at a post-transcriptional level [43].

As a result of unequal segregation of basal cell-fate determinants, the apical NB daughter continues to proliferate, while the basal GMC daughter is committed to differentiate (Fig. 1). The specification of NB and GMC fates is irreversible and no cases of spontaneous de-differentiation of a GMC into a NB have been observed.

\section{Asymmetric cell division in mammalian neural lineages}

The production of the different cell types in the mammalian central nervous system (CNS) occurs in temporally defined, though overlapping, developmental phases. Generally, neurons arise first, followed by astrocytes and oligodendrocytes. This process is largely determined by cellintrinsic changes that alter the differentiation potential of CNS progenitors as development proceeds [51, 52].

Polarized progenitors and division mode during embryonic neurogenesis

Similar to Drosophila NBs, mammalian embryonic neural stem cells, or radial glia (RG) cells, arise from neuroepithelial cells, with which they share pronounced apico-basal polarization. RG cells divide in the ventricular zone (VZ) and they contact the ventricular and pial surfaces of the neural tube through an apical process and a long basal fiber, respectively. At its apical endfoot, each RG cell forms close contacts with its neighboring cells via adherens junctions (AJs) [53, 54].

During the peak of neurogenesis, RG cells execute mainly asymmetric self-renewing divisions to produce either neurons or basal progenitors (BPs) [55]. The newly born neurons and BPs lose both ventricular and pial attachments and migrate basally $[2,56]$. BPs then divide symmetrically in the subventricular zone (SVZ) to give rise to either two BPs, or, as in most cases, to two neurons that migrate further basally [2, 56] (Fig. 2). Another type of neurogenic progenitor with a short basal fiber has been reported to divide adjacent to RG cells, which has led to the proposal that multiple types of neural progenitors co-exist in the VZ [57].

Recently, a new class of RG residing in the outer SVZ of the human, ferret $[58,59]$, and mouse embryonic brain [60] 


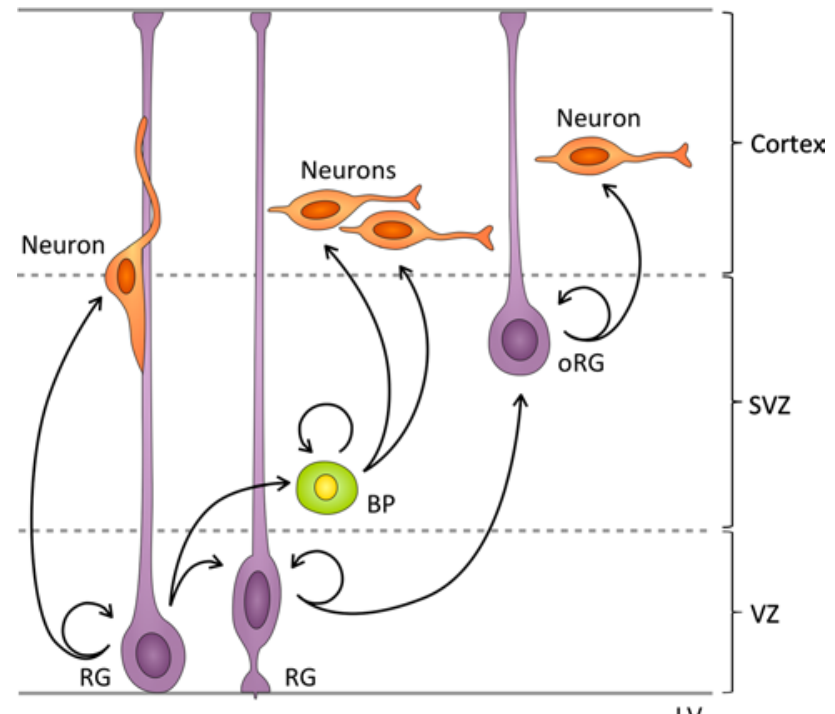

LV

Fig. 2 Patterns of cell division during mammalian embryonic neurogenesis. During the peak period of murine neurogenesis radial glia $(R G)$ cells divide in the ventricular zone $(V Z)$ mainly asymmetrically, generating one RG cell and one neuron, or one RG cell and one basal progenitor $(B P)$, which migrates to the subventricular zone $(S V Z)$. Asymmetric RG divisions also produce outer RG $(o R G)$ cells, which lose their ventricular attachment and translocate to the SVZ, where they divide asymmetrically to produce neurons

has been identified. Murine outer RG (oRG) arise from asymmetrically dividing RG cells and, in contrast to BPs and neurons [60], oRG inherit the basal fiber, but lose their apical attachment [61] and migrate to the SVZ, where they undergo asymmetric self-renewing divisions to produce neurons [60] (Fig. 2).

\section{The Par complex and adherens junctions}

The molecular mechanisms that establish polarity in RG and oRG cells are only partially delineated. The mammalian homologs of the polarity regulators Par3, Par6, and aPKC [62], as well as of Cdc42 [63], localize to RG apical endfeet and appear to serve two main functions: First, they maintain apical AJs integrity, thereby preserving RG polarity and VZ organization, and secondly, they participate in the control of RG cell fate.

Apical assembly of the Par3/Par6/aPKC complex requires $\mathrm{Cdc} 42$ function. Targeted deletion of $\mathrm{Cdc} 42$ disrupts apical localization of Par6 and aPKC [64] and causes loss of AJs [63]. Similarly, conditional depletion of aPKC $\lambda$ in RG leads to loss of AJs, disruption of the $\mathrm{VZ}$, detachment of apical processes from the ventricular surface, and centrosome mislocalization. Despite these polarity defects, neurogenesis occurs normally [65]. This may either indicate that maintenance of AJs integrity and associated polarity are dispensable for cell fate determination, or alternatively, that loss of aPKC $\lambda$ may not completely disrupt the intrinsic polarity of RG, perhaps due to functional redundancy with other aPKC isoforms.

RG cells AJs are formed by three different domains, which are sometimes bisected in an asymmetric fashion by the mitotic spindle during RG divisions [66]. A basal $\beta$-catenin/E-cadherin-positive region and a central $\mathrm{ZO}^{+}$ domain segregate to both daughter cells in the majority of the divisions. In contrast, an apical region enriched for Par3 and aPKC, together with the most apical part of the plasma membrane, which shows localized expression of Prominin-1, have been found to be consistently distributed to only one daughter cell in neurogenic divisions $[66,67]$.

\section{Prominin-1 in the VZ}

Prominin-1 (Prom1) is a multispan transmembrane glycoprotein that is specifically sorted to microvilli and plasma membrane protrusions and localizes to membrane microdomains that are released into the extracellular space [68]. The human homolog of Prom1, CD133, is a cell-surface marker for distinct, malignant populations of CSCs, and has been shown to segregate asymmetrically in a subpopulation of brain CSCs, which we will discuss further below [6]. CD133/Prom1 also segregates asymmetrically in hematopoietic stem and progenitor cells, suggesting a broader and common role in somatic stem and progenitor cells [69]. So far, described phenotypes for genetic depletion of Proml in mice are restricted to retinal degeneration [70]. Therefore, the significance of the asymmetric distribution of Prom1-containing microdomains in RG and nonneural stem cells remains unclear.

\section{Par3 and Numb}

Gain- and loss-of-function studies are conclusive in showing that unequal segregation of Par3/aPKC is responsible for differential cell-fate determination. Forced expression of Par3 increases symmetric RG divisions at the expense of BP generation. In contrast, conditional Par3 depletion increases neurogenesis [71]. The effects of Par3 on RG cell fate depend on Numb and its close relative Numb-like (Numbl). Par3 seems to directly interact with Numb and thereby to modulate its antagonistic effect on Notch signaling [71]. Since Notch activity is involved in the maintenance of RG identity [72], this provides a mechanism by which Par3 promotes RG fate. Interestingly, Numb and Numbl have also been implicated in the maintenance of RG AJs and polarity [73]. Thus, Par3 and Numb/Numbl maintain polarity and balance self-renewal and differentiation of RG cells. 


\section{Par3-independent asymmetry}

Consistent with the lack of apical process, human oRG fail to express the apical regulators Par3 and aPKC [59], yet they retain expression of the RG markers Sox 2 and Pax6 and continue to divide asymmetrically $[58,59]$. This suggests that a currently undefined, Par3-independent, mechanism of polarity and cell fate control exists in oRG cells. An interesting possibility is that this regulatory machinery is dependent on the basal fiber. In support of this, analyses of the contribution of the apical domain and basal RG process to cell-fate determination on murine slice cultures have shown that inheritance of the basal process alone is associated with acquisition of either RG or oRG fate, whereas inheritance of the apical domain in addition to the basal process is required to retain RG identity [61].

Given that the asymmetric inheritance of both the basal process and Par3/aPKC at the apical domain depend on a slight tilting of the mitotic spindle, these observations highlight how crucial the positioning of the mitotic spindle in relation to the apico-basal axis may be for cell-fate determination.

Spindle orientation and centrosome asymmetry

During the peak period of neurogenesis, the majority of RG cells undergo vertical divisions, with the mitotic spindles aligned within $0^{\circ}$ and $30^{\circ}$ of the ventricular surface [74, 75]. A smaller fraction of the cells have an oblique spindle orientation (between $30^{\circ}$ and $60^{\circ}$ ), and only rarely, cells divide with a horizontal cleavage plane $[74,76]$.

\section{Pins/LGN and Insc}

Similar to Drosophila NBs, Pins and Insc homologues play a role in orienting the spindle in RG cells, although some functional differences appear to exist. LGN, an orthologue of Pins, is highly expressed in the VZ and localizes to the lateral membrane of dividing RG cells [77]. Genetic ablation [74] or siRNA-mediated knockdown [61] of $L G N$ lead to increased oblique RG divisions at the expense of vertical divisions. During oblique divisions, the entire apical endfoot with the Par polarity complex is inherited by only one cell, while the other cell remains Par3-negative. This results in abnormal production of oRG cells at the expense of differentiated progeny [61].

Interestingly, Insc seems to oppose LGN function in RG cells [74]. The two proteins do not overlap in their subcellular localization, but rather Insc localizes to an apical crescent in RG cells at prometaphase and to the midzone in anaphase. Forced expression of Insc in the developing mouse cortex increases the frequency of horizontal and oblique divisions [74, 75]. Conversely, conditional inactivation of Insc causes an increased number of vertical divisions [75]. The number of RG cells in the VZ is not affected by changes in Insc expression. However, upon Insc overexpression the overall number of proliferative cells, $\mathrm{Pax}^{+}$progenitors in the outer layers, as well as that of BPs and neurons increases $[74,75]$. Postiglione and colleagues concluded that increased oblique divisions led to increased numbers of BPs directly. Yet, an alternative explanation is that increased oblique divisions may generate more oRG, which in turn produce BPs and neurons [78]. Regardless of the mechanism, these observations are difficult to reconcile with a conserved function of Insc as a cellular linker of the Par complex and LGN/G $\alpha$.

In RG cells, the centrosome localizes to the tip of the apical endfoot and, after duplication, the nascent centrosome predominantly segregates to the differentiating progeny [79]. Thus, although showing stereotypical asymmetric segregation, the pattern of inheritance of nascent and maternal centrosome in RG is opposite to that in Drosophila NBs.

\section{Treacle/Plk1}

The phosphoprotein Treacle has been found to associate with the centrosome and to be critical for correct spindle positioning and mitotic progression. Treacle function appears to depend on its physical interaction with Polokinase 1 (Plk1), a mammalian Polo homolog. In mice hemizygous for Treacle, localization of Plk1 to the centrosome is disrupted. Either Treacle deficiency or pharmacological inhibition of Plk1 prolong mitoses and perturb cleavage planes of RG divisions [80]. This suggests that the Treacle/Plk1 complex acts as a checkpoint that RG cells pass once the mitotic spindle is properly positioned.

In summary, some general ACD principles appear to be conserved between NBs and RG, such as the crucial role of cell intrinsic cues, rather than external signals, in determining the orientation of cell divisions [81]. Yet, organismspecific differences exist in the regulation of cleavage plane and centrosome asymmetry.

\section{Cell fate determination}

Some of the mouse homologs of the cell fate determinants that regulate ACD in Drosophila NBs have been reported to preferentially localize to either the basal fiber or apical domain of RG cells.

\section{Stau2, Prox1, and Trim32}

Staufen2 (Stau2), the mouse homolog of Staufen, is apically localized in RG cells [82, 83]. In vitro cell pair assays with cortical progenitors indicate that it preferentially 
segregates to the daughter that acquires a BP fate [83]. Stau2 is part of a ribonucleoprotein complex that includes the RNA-binding proteins Pumilio2 (Pum2) and DEAD box polypeptide 1 (Ddx1), as well as cargo mRNAs such as the mammalian homologs of prospero and brat, Prosperorelated homeobox 1 (Proxl) [82] and Tripartite-motif containing 32 (Trim32) [83], respectively. Depletion of Stau2, $D d x 1$, or Pum 2 by shRNA results in premature differentiation of RG cells into neurons [82, 83], indicating that the complex is essential for progenitor maintenance. Moreover, Stau 2 knockdown was shown to cause mislocalization and increased levels of Proxl mRNA [82], as well as a more diffuse and symmetric distribution of Trim 32 mRNA [83]. Since Prox 1 is known to mediate cell-cycle exit and neurogenesis in the neural retina [84] and Trim32 induces neurogenesis [85], these data suggest that, similar to its Drosophila homolog, Stau2 binds and localizes neurogenic determinants away from the self-renewing daughter.

Trim32 is an E3-ubiquitin ligase and has been suggested to promote neuronal differentiation by activating specific microRNAs, such as Let-7 [85], and by enhancing the transcriptional activity of retinoic acid receptor- $\alpha$ [86]. Additionally, Trim 32 binds to the transcription factor c-Myc and targets it for degradation, thus coupling cell-fate specification with cell-cycle exit [85]. Trim32 has also been shown to interact with membrane aPKC $\xi$ [87]. It has been proposed that this interaction prevents its nuclear translocation and consequently c-Myc degradation in neural progenitors, allowing maintenance of an undifferentiated and proliferative state.

\section{Asymmetry and cell cycle}

Cell-fate determination in the neural lineage is tightly linked to cell-cycle length. Indeed, lengthening G1 has been shown to be necessary and sufficient to switch neural progenitors into neurogenesis [88]. In cyclin-dependent kinase 2 and $4(\mathrm{Cdk} 2 / 4)$ double-knockout mice, neural progenitors exhibit G1 phase lengthening, which correlates with increased spontaneous differentiation in vitro and loss of BPs and increased neuronal production in vivo [89]. Interestingly, recent work indicates that asymmetrically dividing RG cells unequally segregate Cyclin D2, a positive regulator of G1 progression [90]. With the onset of neurogenesis, both Cyclin D2 protein and mRNA become enriched at the basal endfeet of RG cells [90, 91]. This biased distribution has been proposed to result from active transport and local translation of Cyclin D2 (Ccnd2) mRNA [90]. Upon asymmetric RG cell division, Cyclin D2 preferentially segregates to the nucleus of the self-renewing daughter [90], where it plays an active role in promoting RG cell fate, as suggested by functional studies $[90,92]$. Together, these observations not only propose a mechanistic integration between cell-cycle regulation and cell-fate determination but also provide support to the view that inheritance of the basal process may be key for RG cell-fate specification.

Cellular divisions in the adult neurogenic niche

By early postnatal life, following the completion of the neurogenic period, RG cells retract their processes and differentiate into astrocytes and ependymal cells [93, 94]. Yet, in the rodent adult brain, two main neurogenic sites remain: the SVZ of the lateral wall of the lateral ventricle $[95,96]$ and the subgranular zone of the dentate gyrus of the hippocampus [97, 98]. In these regions, a subpopulation of RG-derived cells, which express glial fibrillary acidic protein (GFAP) and Nestin, act as neural stem cells (NSCs) [99, 100]. Adult SVZ NSCs, frequently referred to as type B cells, divide to generate transit-amplifying progenitors (TAPs) [101] and oligodendrocyte precursor cells (OPCs) [102]. TAPs and OPCs in turn produce neuroblasts, also called type A cells [99], and oligodendrocytes [102], respectively (Fig. 3a).

Similar to RG cells, adult SVZ NSCs are polarized. They extend a long basal process that contacts a blood vessel, and a small ciliated apical domain that touches the lateral ventricle and forms AJs with the ependymal layer $[103,104]$, the integrity of which depends on Numb activity [105]. Due to the morphological similarities, it could be reasonably assumed that molecular mechanisms of polarity generation and maintenance are shared between RG and adult NSCs. However, this remains to be investigated.

Ex vivo analyses have identified a proliferative or "activated" GFAP ${ }^{+}$population in the adult SVZ that distinguishes itself from a quiescent $\mathrm{GFAP}^{+}$NSC population by the expression of epidermal growth factor receptor (EGFR) [106]. A recent study has demonstrated that the majority of NSCs in situ are actually quiescent and only $8.6 \%$ of $\mathrm{GFAP}^{+}$cells in the adult SVZ actively proliferate [107]. Given the high level of quiescence, it is not surprising that the in vivo division pattern of adult NSCs has not been determined yet. In situ labeling studies, however, suggest that following NSC division, TAPs undergo three amplifying divisions before giving rise to neuroblasts [107]. These data are in line with earlier in vitro time-lapse imaging studies of SVZ-derived progenitors that proposed that TAPs predominantly divide symmetrically for several rounds to expand the TAP cell pool and to generate neuroblasts [108]. This suggests that isolated adult SVZ neural progenitors preserve the cell-division pattern that they display in vivo, arguing for cell-autonomous regulation of lineage progression. Interestingly, in their in vitro imaging analyses, Costa and colleagues detected $\mathrm{GFAP}^{+}$cells that divide to self-renew and to give 
Fig. 3 Progenitor divisions in the postnatal and adult brain. a Neural stem cells (NSCs) in the adult ventricular $(V)$-subventricular zone $(S V Z)$ neurogenic niche extend contacts to blood vessels and the lateral ventricle $(L V)$ and are surrounded by ependymal cells (ECs). NSC divisions produce transit amplifying progenitors (TAPs) and oligodendrocyte precursor cells $(O P C s)$, which in turn divide to generate postmitotic progeny. b Postnatal cortical astrocytes undergo symmetric proliferative divisions. $\mathbf{c}$ In the white matter, adult OPCs divide either symmetrically or asymmetrically to self-renew and produce differentiated oligodendrocytes
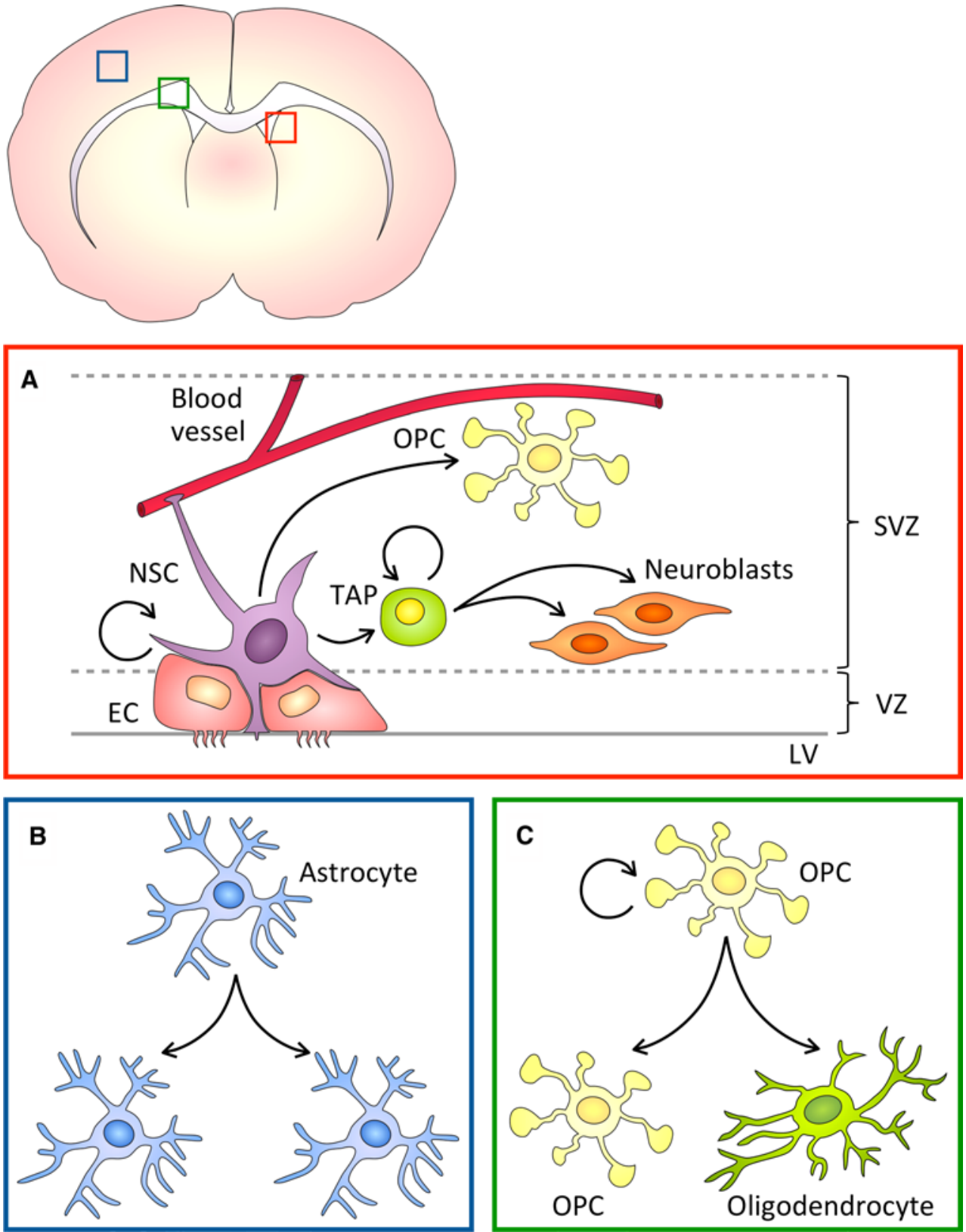

rise to TAPs, suggesting that adult NSCs indeed undergo ACD [108].

The adult ventricular-subventricular neurogenic niche encompasses the ventricle with cerebrospinal fluid, ependymal cells, NSC progeny, and capillaries [104, 109]. The observation that NSCs contact those components raises the attractive possibility that extrinsic cues such as selfrenewal factors emitted by capillaries [110, 111] and growth factors in the cerebrospinal fluid [112] may promote NSC proliferation. Interestingly, in vitro studies have shown that a fraction of adult NSCs asymmetrically distributes Notch and EGFR between daughter cells, thus producing progeny with differential response to extrinsic cues. In neurosphere cultures, high Notch activity and EGFR expression levels correlate with high self-renewal capacity [110]. Asymmetric EGFR levels between sibling cells are regulated at both transcriptional and post-translational levels, by different yet complementary mechanisms. First, activated Notch is unequally distributed during NSC division and it has been shown to directly regulate Egfr transcription [110]. Next, during cytokinesis, Dyrk1a kinase is asymmetrically segregated to the EGFR ${ }^{\text {high }}$ daughter, where it prevents EGFR degradation [113]. Unequal EGFR expression between sibling cells appears to be a common cell-fate switch in embryonic and adult NSCs [114]. Together, this suggests that cell-intrinsic processes 
and signals from the niche synergistically regulate NSC fate.

EGFR and Notch are part of the signaling pathways involved in cancer and these pathways are frequently altered in brain carcinogenesis. Implications of alterations in these pathways on stem and progenitor cell division mode in the context of brain cancer will be discussed below.

\section{Asymmetric divisions during gliogenesis}

In rodents, the generation of astrocytes starts during embryonic development and peaks at neonatal stages. Astrocytes, which are commonly identified by expression of GFAP [115], can arise from RG cells [93, 116-118], gliarestricted progenitor cells in the white and gray matters $[116,119]$ and from local proliferation-i.e., symmetric expansion-of differentiated astrocytes [120] (Fig. 3b). However, due to unavailability of lineage-specific markers, the sequence of developmental steps that glia-restricted precursor cells undergo before giving rise to mature astrocytes are not yet clear.

Oligodendrocyte precursor cells (OPCs), on the other hand, are characterized by the expression of plateletderived growth factor receptor alpha (PDGFR $\alpha)$ [121], Olig2 [122], and NG2 [123]. They originate at different developmental stages in discrete regions of the CNS, from where they migrate before differentiating into myelinating oligodendrocytes [121, 124, 125] or protoplasmic astrocytes [119].

In the adult brain, OPCs are widespread in the gray and white matters and continue to divide throughout life, making up the largest proliferative population in the postnatal brain $[126,127]$. In vivo lineage tracing of $\mathrm{NG}^{+}$OPCs has revealed that the differentiation potential of postnatal and adult OPC becomes restricted to oligodendrocytes. Live imaging of single $\mathrm{NG}^{+}$OPCs in mouse brain slices has shown that at early postnatal stages OPCs self-renew and generate differentiated progeny by undergoing either asymmetric self-renewing, symmetric proliferative or symmetric differentiating divisions [128]. Detailed immunohistochemistry analyses of dividing OPCs in the adult mouse brain have indeed confirmed the presence of symmetrically dividing OPCs producing two $\mathrm{NG}^{+}$OPCs, and asymmetrically dividing OPCs that generate one $\mathrm{NG}^{+} \mathrm{OPC}$ and one NG2-negative daughter (Fig. 3c). In vitro studies further indicate that the NG2-negative daughter cell is committed to differentiation [3]. These findings demonstrated that glial cells in the adult mammalian brain and, particularly mammalian OPCs, can undergo ACD to self-renew and generate mature oligodendrocytes at a one-to-one ratio. A first glimpse of the mechanism involved in asymmetric cell-fate determination in OPCs comes from in vitro data showing that NG2 not only tracks self-renewing fate but also instructs EGFR to co-segregate to the proliferative progeny. Thereby, each asymmetric OPC division generates one $\mathrm{NG}_{2}{ }^{+} \mathrm{OPC}$ that activates EGFR and self-renews, and a NG2-negative cell that becomes a differentiated oligodendrocyte [3].

NG2 is a chondroitin sulfate proteoglycan (CSPG) and part of the proteoglycan family, which regulates many signaling pathways implicated in cancer, including growth factor receptor tyrosine kinases (RTKs), as well as cell-microenvironment interactions [129]. In the brain, NG2 is only expressed by OPCs and pericytes, suggesting that it constitutes a cell type-specific determinant of cell fate. Future studies are expected to reveal potential interactions of NG2 with molecules of the conserved asymmetry regulatory machinery. Such data will provide mechanistic insights into the regulation of $\mathrm{ACD}$ in the adult brain.

\section{Asymmetric cell division and cancer}

Cancer is caused by the step-wise acquisition of genetic mutations, which provide a survival benefit to the affected cell(s). Despite the heterogeneous nature of the disease, most cancers can be described by a few organizing principles, the so-called "hallmarks of cancer", a term that has been coined by Hanahan and Weinberg over the past decade $[130,131]$. Among such "hallmark capabilities" of cancer cells are their ability to sustain proliferative signaling, evade growth suppressors, and resist cell death. In addition, cancer cells lose cell adhesion, change their shapes, acquire novel cell-fate characteristics and secrete factors, including metalloproteases that alter their environment. These changes are associated with the ability of cancer cells to invade adjacent tissue and to migrate to distant sites to form metastases. Moreover, it has been proposed that the acquisition of distinct hallmarks relies to a great extent on genomic instability [131].

Although it is clear that these cellular features are complementary and might indeed be mechanistically linked, individually, they provide a basic framework to understand the biological complexity of cancers. Genetic mutations linked to cancer co-opt molecular pathways that are important regulators of normal development and cellular capacities such as proliferation, differentiation, and cell-cycle and growth control. It is feasible that cancer-causing mutations also hijack ACD regulatory pathways, since these orchestrate cellular proliferation, cell-cycle progression, cell shape and fate, and possibly genomic stability. Below, we discuss how this hypothesis has been addressed in fly NBs and murine models of human cancers as well as human cancer cell lines. 
ACD as a tumor suppressor mechanism: evidence from Drosophila neuroblasts

The first suggestion that loss of ACD might be involved in tumorigenesis came from discoveries in Drosophila. Studies of loss-of-function mutations in key regulators of ACD, including $\operatorname{lgl}$ [132], aurA [31, 32], polo [30], numb [10, 31, 32], and brat [10, 43, 44, 50], revealed hyperproliferative phenotypes in situ. In these mutants, presumably due to defective ACD, NBs divide more symmetrically and generate mis-specified progeny that fails to exit the cell cycle and differentiate, but rather proliferates continuously (Fig. 4).

To study the effects of sustained disruption of ACD in fly NBs beyond the lifespan of the fruit fly, the mutant tissues were implanted into the abdomen of adult wild-type hosts. Interestingly, the brain tissue transplants from larvae mutant for $l g l$ and $d l g$ [133], or for pins, numb, mira, pros, or brat [134] but not wild-type transplants, grew expansively and invaded the host. Upon subsequent rounds of allografting, the ACD mutant tissues contained cells with aberrant karyotypes and multiple centrosomes [134] (Fig. 4). Appearance of these defects correlated with higher ability to re-grow tumor-like masses upon re-implantation. These experiments not only support the observation that impairment of ACD and the resulting loss in cell-fate determination can cause hyperproliferation but also suggest that loss of polarity and spindle control may be an important step in the neoplastic transformation of asymmetrically dividing stem and progenitor cells [135].
The integrity of the mitotic spindle and centrosomes is paramount to a stable genome and disruption of mitotic spindle checkpoints and centrosomes have been frequently observed in human cancer. Distinct studies have investigated the relevance of centrosome integrity for normal growth. Hypermophic mutants for polo, aurA, and dsas-4 fail to properly regulate the centrosome in both asymmetrically dividing NBs and symmetrically dividing epidermal cells. Surprisingly, allografting experiments have shown that while transplants of larval brain tissues from polo, aurA, or dsas-4 mutants lead to formation of masses reminiscent of tumors, implanted epidermal tissue from the same mutants never forms masses [136]. These observations indicate that loss of centrosomal integrity can cause hyperplastic growth of asymmetrically dividing cells, but not of cells undergoing symmetric divisions. Overexpression of the protein kinase Sak/Plk4 in NBs leads to supernumerary centrosomes, aberrant mitotic spindle positioning, and mild hyperproliferation. Upon allografting, NBs overexpressing Sak also form tumor-like masses, although at lower rates than ACD mutant NBs [137]. Given that only a small fraction of the Sak mutant cells display mislocalized expression of cortical regulators and therefore impaired ACD [137], the data suggest that losing centrosomal integrity in itself does not initiate hyperproliferative phenotypes and associated mass formation. Instead, these seem to be secondary effects of ACD disruption.

Due to the intertwined control of polarity, spindle orientation, cell-fate determination, and proliferation, it is challenging to uncouple those events and to reveal a temporal

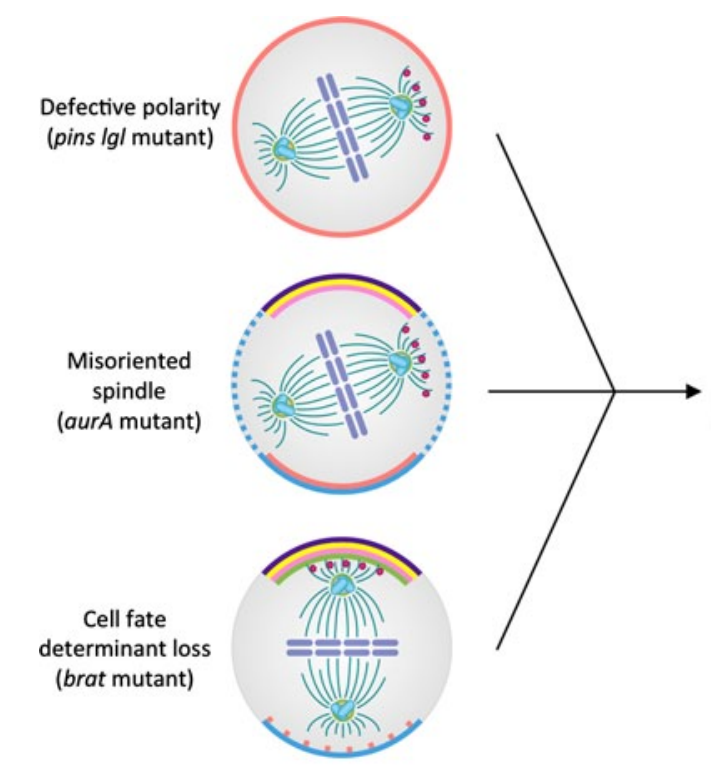

Fig. 4 Defects in polarity, spindle orientation, or cell-fate specification disrupt asymmetric division and result in hyperproliferation and loss of differentiation of Drosophila neuroblasts. Serial allografting of asymmetry-defective, hyperproliferative neuroblasts leads to chromosomal abnormalities and aneuploidy 
sequence of defects. However, mounting genetic evidence suggests the provocative possibility that failure of basal cell fate determinants to segregate properly initiates a cascade of events that starts with aberrant proliferation of NBs and that ultimately leads to the neoplastic transformation of stem or progenitor cells. Hyperproliferative NBs acquire spindle defects such as supernumerary centrosomes and overrule spindle checkpoints, which causes genomic instability and thus introduces cellular phenotypes similar to those found in human brain cancer [138]. Largescale forward genetic screens in Drosophila cancer models will be useful in clarifying the sequence of events leading to massive outgrowth of larval brain tissue and those data are expected to inform studies of human brain cancer development.

Relevance of ACD during cancer formation

\section{Genetics of ACD regulators in cancer}

Cancer is essentially a genetic disease and arises from a cell that has acquired a cancer-initiating mutation. The accumulation of additional genetic and/or epigenetic alterations cause the cancer cells to further progress and grow, invade, and metastasize. Most frequently, mutations are singlenucleotide changes or point mutations. Additional genetic aberrations found in cancer cells are smaller chromosomal changes such as translocations and insertions, as well as regional amplifications and deletions. However, many cancer cells also exhibit loss or gain of entire chromosomes [139]. Emerging evidence indicates that key regulators of ACD are mutated in multiple cancer types and introduction of such mutations in murine models cause cancer-associated phenotypes (Table 1). For instance, a recent genomewide screen for micro-deletions across a range of primary and cultured human tumor cells identified the deletion of polarity regulators in numerous human epithelial tumor cells. Such deletions include PARD6 (PAR6) in lung cancer, PARD3 (PAR3) in lung, head and neck, esophagus, prostate and bladder cancers, and $D L G 2$ in lung and cervical cancers [140, 141].

Malignant brain tumors are classically categorized into three main variants: astrocytomas, oligodendrogliomas, and mixed oligoastrocytomas. Grade IV astrocytoma, also known as glioblastoma multiforme (GBM), is the most aggressive type of glioma. The Cancer Genome Atlas has provided a comprehensive view of the genomic landscape of GBM [142]. The study revealed that a small number of signaling pathways are frequently mutated in these tumors. Single-nucleotide variations within genes implicated in ACD regulation are rarely found in GBM (Andor and Petritsch; unpublished observations). Yet, expression of ACD regulators is frequently altered in many types of human cancers (see Table 1 for a list), including gliomas [3]. It is therefore likely that regulators of ACD are subjected to epigenetic and/or posttranslational modifications that influence their expression levels in cancer cells. Examples of such regulations have been provided for a small number of ACD regulators and these will be discussed below.

\section{$A C D$ and the cellular origin of (brain) cancer}

Most cancers arise from a single cell, i.e., they have a clonal origin. Genetically engineered mouse model (GEMM) studies suggest that in several organs, including the brain, the cellular origin of cancer might be a stem or progenitor cell.

Despite their clonal origin, many cancers are diverse and have significant intratumoral genetic and phenotypic heterogeneity. Underlying genetic factors and the unique microenvironment within each tumor contribute to its individual evolution and heterogeneity. The effects of genetic heterogeneity and the microenvironment on the mode of cell division of the stem and progenitor cells of origin are yet unknown. Our recent studies indicate that the rates of ACD are different between tumors of a single tumor type [3] and may have to be determined individually for each tumor.

Given the difficulty of studying cancer initiation in human patients, the development of GEMMs that recapitulate key aspects of the disease has been crucial for elucidating the cellular and molecular events occurring at different stages of tumorigenesis. Sophisticated GEMMs modeling key genetic alterations in the core signaling pathways found to be mutated in GBM, namely the p53 pathway, the Retinoblastoma (RB) pathway and the RTK signaling pathways, including deletion of the neurofibromatosis type 1 (NF1) gene [143], have recently become available [144]. These mice have been used to investigate the cellular origin of astrocytoma and oligodendroglioma.

These GEMM studies have shown that the sequence by which cellular controls become dysregulated during oncogenesis can vary between cancer types. However, increased proliferation, enhanced self-renewal, and evasion from cell cycle control tend to be early events during cancer development. In contrast, immortalization, genomic instability, invasion and metastasis are considered intermediate or late events [131]. The molecular mechanisms and temporal regulation of defects in polarity and ACD in human cancer initiation and progression remain poorly understood. Below, we discuss the emerging role of ACD dysregulation in promoting hallmark capabilities of cancer cells with a focus on data obtained from GEMMs of glioma.

\section{Abnormal proliferation and self-renewal}

Asymmetric divisions are a key mechanism to ensure tissue homeostasis. In normal stem and progenitor cells, ACD 
Table 1 Asymmetric cell division regulators and their role during cancer formation and progression

\begin{tabular}{|c|c|c|c|}
\hline Gene & Chromosomal location & $\begin{array}{l}\text { Genetic alteration and/or expression } \\
\text { in human tumors }\end{array}$ & $\begin{array}{l}\text { Cancer-associated phenotypes in in vivo } \\
\text { mouse models }\end{array}$ \\
\hline$A U R A K$ & $20 \mathrm{q} 13.2-\mathrm{q} 13.3$ & $\begin{array}{l}\text { Amplified and overexpressed in diverse human } \\
\text { tumors [194], including breast [195], ovarian [196], } \\
\text { gastric [197], bladder [198], and pancreatic [199] } \\
\text { cancers }\end{array}$ & $\begin{array}{l}\text { Pharmacological inhibition in breast } \\
\text { [200] and ovarian [201] cancer cells } \\
\text { and siRNA-mediated depletion in } \\
\text { laryngeal cancer cells [202] prevent } \\
\text { metastasis upon xenotransplantation }\end{array}$ \\
\hline CSPG4 (NG2) & $15 q 24.2$ & $\begin{array}{l}\text { Overexpressed in astrocytomas [129] and oligoden- } \\
\text { drogliomas [3] }\end{array}$ & $\begin{array}{l}\text { Pericyte deficiencies in Cspg4 knockout } \\
\text { mice lead to aberrant tumor vasculari- } \\
\text { zation [203] }\end{array}$ \\
\hline$D L G 2$ & $11 \mathrm{q} 14.1$ & $\begin{array}{l}\text { Localizes within a large common fragile site [204]. } \\
\text { Expression downregulated in oligodendroglioma [3] }\end{array}$ & Not determined \\
\hline$H U G L-1$ & $17 \mathrm{p} 11.2$ & $\begin{array}{l}\text { Gene loss in } 75 \% \text { of colorectal cancers [205]. } \\
\text { Reduced expression in melanoma, breast, lung, } \\
\text { prostate [206], and ovarian cancers [207] }\end{array}$ & $\begin{array}{l}\text { Lgll knockout mice have pre-cancerous } \\
\text { rosette-like structures in the brain. Neu- } \\
\text { ral progenitor cells fail to differentiate } \\
\text { and to exit the cell cycle [147] }\end{array}$ \\
\hline$H U G L-2$ & $17 q 24-q 25$ & $\begin{array}{l}\text { Loss or aberrantly localized in gastric adenocarcino- } \\
\text { mas [208]. Reduced expression in colorectal and } \\
\text { breast cancers [209] }\end{array}$ & $\begin{array}{l}\text { Forced expression in breast cancer cell } \\
\text { lines reduces their metastatic potential } \\
\text { upon subcutaneous xenotransplantation } \\
\text { [210] }\end{array}$ \\
\hline MSI1 & $12 \mathrm{q} 24.1-\mathrm{q} 24.31$ & $\begin{array}{l}\text { Upregulated in oligodendrogliomas [3], astrocytomas } \\
\text { [211], colorectal tumors [212], and endometrial } \\
\text { cancers [213] }\end{array}$ & $\begin{array}{l}\text { Msil knockdown reduces growth of } \\
\text { xenografted glioblastoma [214] and } \\
\text { colon adenocarcinoma cells [215] }\end{array}$ \\
\hline MSI2 & $12 \mathrm{q} 24.1-\mathrm{q} 24.31$ & Increased expression in CML [153] & $\begin{array}{l}\text { Loss of function in HSCs expressing } \\
\text { NUP98-HOXA9 reduces leukemia } \\
\text { growth in vivo [153] }\end{array}$ \\
\hline$N U M B$ & $14 \mathrm{q} 24.3$ & $\begin{array}{l}\text { Reduced protein levels in some mammary carcino- } \\
\text { mas [151], NSCLC [216] and blast crisis of CML } \\
\text { [153] }\end{array}$ & $\begin{array}{l}\text { Ectopic expression in HSCs transduced } \\
\text { with BCR-ABL and NUP98-HOXA9 } \\
\text { reduces the incidence and propagation } \\
\text { of blast crisis in vivo [153] }\end{array}$ \\
\hline PARD3 & $10 \mathrm{p} 11.21$ & $\begin{array}{l}\text { Reduced expression in melanoma, breast, lung, and } \\
\text { bladder cancers [149] }\end{array}$ & $\begin{array}{l}\text { In the presence of relevant oncogenic } \\
\text { mutations, loss of Par3 favors forma- } \\
\text { tion of keratoacanthomas [150] and } \\
\text { increases mammary tumor growth and } \\
\text { metastasis [149] }\end{array}$ \\
\hline PARD6A & $16 q 22.1$ & $\begin{array}{l}\text { Increased expression [217] or mis-localized [173] } \\
\text { in low- and high-grade breast cancers }\end{array}$ & $\begin{array}{l}\text { Expression of a dominant negative form } \\
\text { in mammary carcinoma cells reduces } \\
\text { incidence of metastases [166] }\end{array}$ \\
\hline$P L K 1$ & $16 \mathrm{p} 12.2$ & $\begin{array}{l}\text { Increased expression in several tumors, including } \\
\text { NSCLC [218], gastric [219], ovarian [220], pros- } \\
\text { tate [221], bladder [222], breast [223], head and } \\
\text { neck [224] cancers, and gliomas [225] }\end{array}$ & $\begin{array}{l}\text { siRNA-mediated depletion in bladder } \\
\text { cancer [222] and GBM [226] cell lines } \\
\text { and pharmacological inhibition in } \\
\text { breast cancer [223] and glioma cells } \\
\text { [226] impairs/delays tumor growth in } \\
\text { xenograft models }\end{array}$ \\
\hline PRKCI & $2 \mathrm{p} 21$ & $\begin{array}{l}\text { Overexpressed in NSCLC [227], breast [228], ovar- } \\
\text { ian [229], and prostate [230] cancers }\end{array}$ & $\begin{array}{l}\text { Expression of a dominant negative } \\
\text { form in lung cancer cells [231] and } \\
\text { siRNA-mediated depletion in prostate } \\
\text { cancer cells [230] reduce tumorigenic- } \\
\text { ity in vivo. Required for Ras-mediated } \\
\text { transformation of intestinal epithelial } \\
\text { cells [168] }\end{array}$ \\
\hline SCRIBI & $8 \mathrm{q} 24.3$ & Reduced expression or mis-localized in glioma [232] & $\begin{array}{l}\text { Loss of Scrib predisposes to cMyc trans- } \\
\text { formation in mammary epithelia [233] }\end{array}$ \\
\hline TRIM3 & $11 \mathrm{p} 15.5$ & $\begin{array}{l}\text { Loss of heterozygosity in some gliomas [234]. } \\
\text { Downregulated in a subset of gliomas [235], } \\
\text { including oligodendrogliomas [3] }\end{array}$ & $\begin{array}{l}\text { Knockdown increases incidence of } \\
\text { PDGF-driven gliomas in } p 21 \text {-deficient } \\
\text { mice [235] }\end{array}$ \\
\hline
\end{tabular}


balances proliferation and self-renewal with cell-cycle exit and differentiation. Disruption of ACD leads to aberrant self-renewal and impairs differentiation, and could therefore constitute an early step in the neoplastic transformation of stem and progenitor cells.

In a GEMM of oligodendroglioma, in which the viral oncogene $v e r b B$ is expressed under the control of the $S 100 \beta$ promoter in a $p 53$ hemizygous background [145], $\mathrm{NG}^{+}$OPCs expand and initiate tumor development [146]. Detailed cellular analyses in this model demonstrated that premalignant $\mathrm{NG}_{2}{ }^{+}$OPCs display a higher frequency of symmetric self-renewing divisions at the expense of asymmetric differentiating divisions, when compared with nonneoplastic OPCs (Fig. 5). Remarkably, NG2+ OPC-like cells isolated from human oligodendrogliomas also exhibit defective ACD, leading to an overproduction of daughter cells that inherit both NG2 and EGFR [3]. Furthermore, bioinformatic analyses revealed altered expression of 15 conserved ACD regulators in human oligodendroglioma [3]. This suggests that defects in ACD may occur during neoplastic transformation of OPCs and may contribute to oligodendroglioma formation. An emerging scenario for the early events of OPC transformation is that NG2 levels are upregulated early in tumorigenesis in response to expression of verbB, which mimics constitutively active EGFR signaling. Abundance of both molecules disrupts the asymmetric distribution of NG2 and EGFR during OPC division. In the normal adult brain, the OPC progeny negative for these two molecules enters the path of differentiation. In premalignant OPCs, however, NG2/EGFR segregates to both daughter cells, causing their abnormal proliferation (Fig. 5). The molecular details of how

A

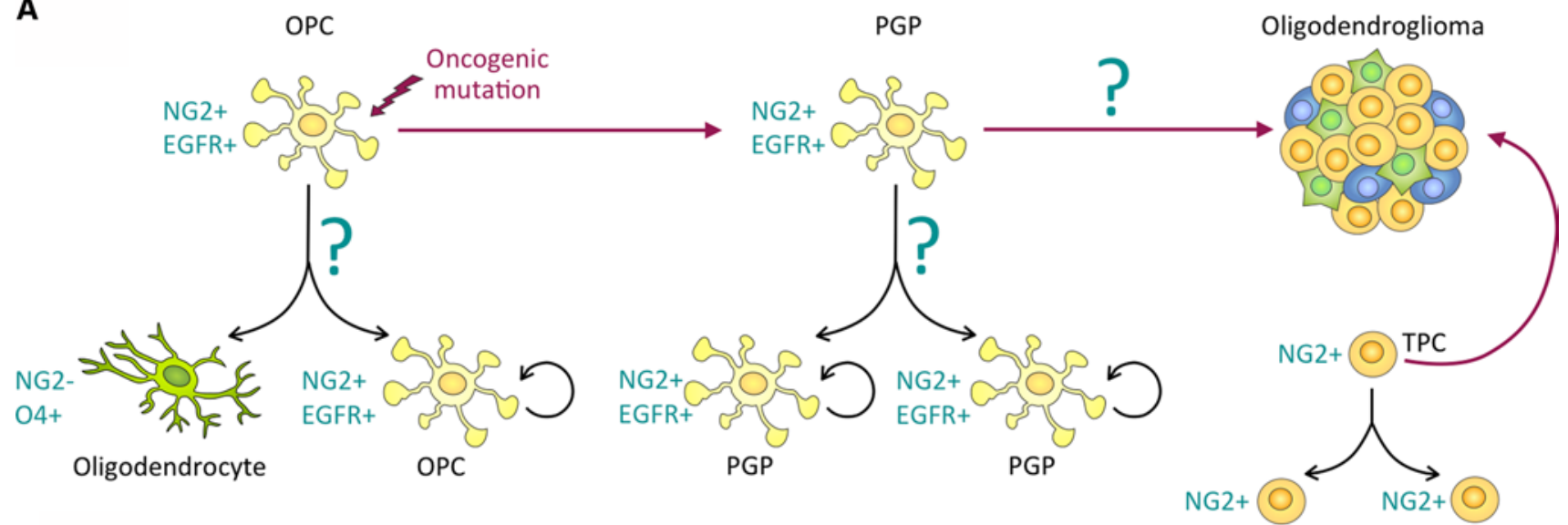

B

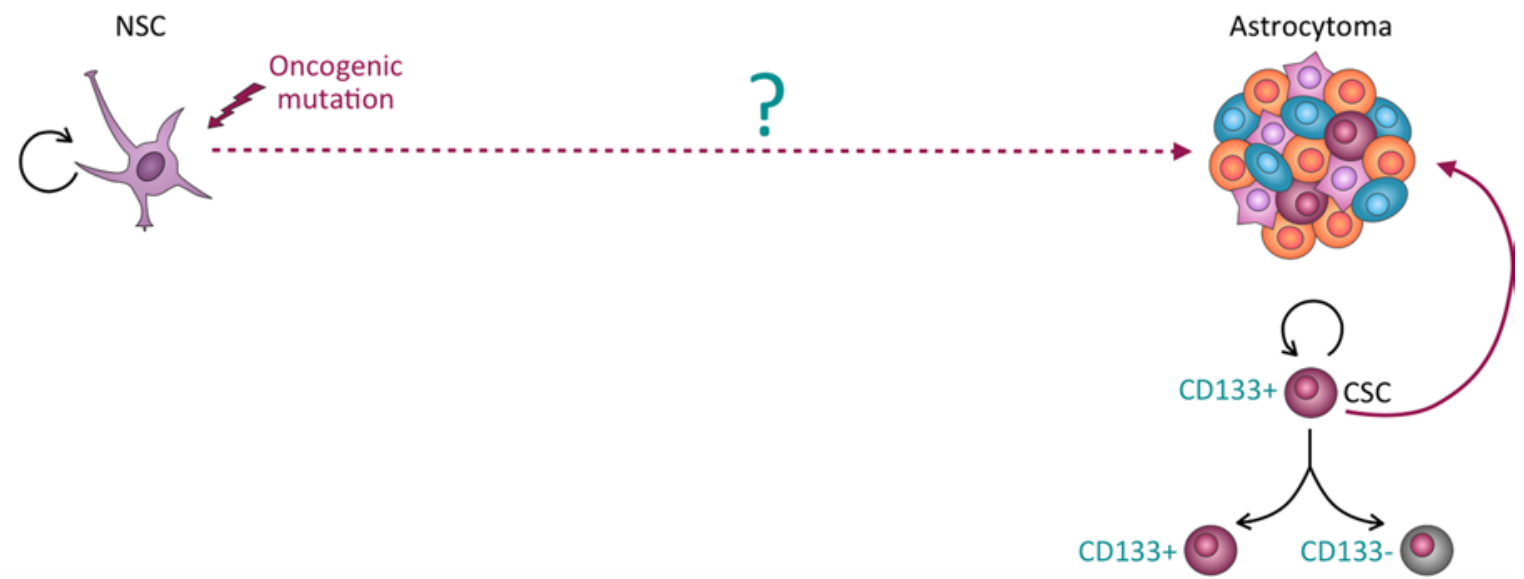

Fig. 5 Cellular origin of malignant gliomas. a Oligodendrocyte precursor cells $(O P C s)$ in the adult brain can divide asymmetrically to give rise to a self-renewing $\mathrm{NG}^{+} \mathrm{OPC}$ and a differentiated $\mathrm{NG}^{-}$ $\mathrm{O}^{+}$oligodendrocyte. In $p 53$ hemizygous mice, expression of the viral oncogene verbB in OPCs disrupts asymmetric OPC division and causes hyperproliferation of symmetrically dividing premalignant glioma precursor $(P G P)$ cells, which, following unknown transformative events, eventually give rise to oligodendrogliomas. Similar to their human counterparts, murine oligodendrogliomas contain symmetrically dividing $\mathrm{NG}^{+}$tumor-propagating cells (TPCs). b Inducing oncogenic mutations of core signaling pathways (e.g., inactivation of the $\mathrm{p} 53$ and $\mathrm{Rb}$ tumor suppressor pathways and activation of RTK signaling) in mouse neural stem cells (NSCs) leads to formation of tumors with features of high-grade astrocytomas. CD133 ${ }^{+}$cancer stem cells (CSCs) isolated from human high-grade astrocytomas selfrenew through symmetric and asymmetric cell divisions 
NG2/EGFR asymmetry is established in OPCs remain to be fully elucidated, and it is possible that verbB expression also affects other conserved ACD regulators.

Studies of the central nervous system of mice lacking Lgll, one of two mammalian orthologues of Drosophila $l g l$, have revealed precancerous brain lesions and prenatal death due to hydrocephalus. Misregulation of Lgl1 disrupts downstream localization of cell-fate determinants, decreases differentiation, and increases proliferation and apoptosis. Furthermore, neural progenitors in prenatal Lgll-knockout mice show loss of AJs [147]. It is interesting that loss of polarity or cell-fate regulation through mutation of $a p k c, l g l$, or other polarity regulators is sufficient to induce massive hyper-proliferation in Drosophila NBs. In contrast, in mammalian epithelia and progenitor cells, loss of ACD regulators leads to tissue disorganization and hyperplasia [147, 148], but does not appear to be sufficient to initiate tumor formation $[149,150]$. Functional redundancies between the regulators of ACD have been observed in Drosophila and they may mask the role of ACD in tumor initiation in mammalian GEMMs.

\section{Growth suppressor evasion}

Mounting evidence points to a role for the cell-fate determinant NUMB as a tumor suppressor in distinct types of human cancers. In breast cancers, NUMB protein levels are frequently reduced or lost and inversely correlate with tumor grade [151] and patient prognosis [152]. In primary breast tumor cell cultures, those with low or no NUMB expression, referred to as class 1 , not only display increased NOTCH activity [151] but also a reduction of TP53 protein levels [152]. Forced-expression of $N U M B$ in class 1 cells significantly reduces NOTCH activity and cell proliferation [151] and restores normal TP53 levels [152].

Numb has been found to physically interact and stabilize p53 by preventing its ubiquitination and degradation induced by the E3 ubiquitin ligase HDM2 [152]. In primary ErbB2-driven mouse mammary carcinoma cells, p53 is unstable, and attenuated p53 levels switch the mode of cell division from asymmetric to symmetric, leading to geometric cell expansion [5]. Although it is not clear whether in this model the levels of Numb protein are also affected, these observations suggest that downregulation of NUMB/TP53 in human breast cancers may cause a bias towards symmetric divisions.

Reduced NUMB levels are also observed during the progression of human chronic myeloid leukemia (CML) to blast crisis and, again, this is associated with increased NOTCH signaling and reduced TP53 activity [153]. In a mouse model of myeloid blast crisis driven by co-expression of the oncogenic fusion proteins BCR-ABL and NUP98-HOXA9, it was found that overexpressing Numb or inhibiting Notch activity reduces the incidence and propagation of blast crisis. Importantly, in the absence of p53, ectopic Numb had no impact on leukemic cell growth, indicating that the effects of Numb are solely dependent on p53.

In normal mouse hematopoietic stem cells (HSCs), Notch activity is required for the maintenance of an undifferentiated state [154]. When isolated and cultured under differentiating conditions, HSCs divide to give rise to a Notch $^{+}$HSC and a differentiating daughter that inherits Numb and downregulates Notch. Transduction with NUP98-HOXA9 causes Notch $^{+}$HSCs to grow expansively [4]. This suggests that Notch overactivation may mediate leukemic growth, at least in part, by promoting symmetric expansion of more immature cells.

Underexpression of NUMB in the above-mentioned tumors appears to be a consequence of posttranscriptional modulation and not of genetic alterations affecting the $N U M B$ locus. In breast cancer, loss of NUMB expression results from increased proteasomal degradation [151]. Downregulation of Numb during blast crisis has been proposed to be mediated, at least in part, by Musashi2 (Msi2) [153]. Depletion of MSI2 in cell lines from patients with CML blast crisis increased NUMB protein levels and led to reduced cell proliferation and apoptosis induction in vitro [155]. Similarly, Msi2 knockdown in mouse HSCs transduced with $B C R-A B L$ and NUP98-HOXA9 resulted in significant leukemic growth impairment in vivo [153]. The Msi family members are evolutionary conserved RNA-binding proteins. In Drosophila, Msi is required for ACD of the sensory organ precursor cell in the peripheral nervous system and its main in vivo target is tramtrack69 mRNA [156]. Two Msi family genes have been identified in mammals, Msil and Msi2. Msi1 is selectively expressed in neural progenitor cells [157] where it has been shown to repress Numb translation [158]. It is thus thought that Msi2 may regulate Numb protein levels by a similar mechanism.

The observation that NUMB stabilizes TP53 provides a connection between evasion of growth suppression and genomic instability. Disruption of ACD and loss of p53 due to lack of NUMB are therefore expected to increase the possibilities of malignant transformation. Moreover, by eliminating the antagonistic effect on NOTCH signaling, reduced NUMB levels would also lead to maintenance of an undifferentiated state and abnormal self-renewal. Further studies are required to test this model and to determine if the mechanisms operating in breast cancer and the blast crisis of CML are conserved in tumors from other tissues. Loss of p53 in the adult mouse brain expands the pool of type A cells and quiescent B cells and leads to increased self-renewal, but not to tumor formation [159]. In a GEMM of astrocytoma, combined loss of p53 and Pten impairs NSC differentiation and induces tumor formation [160]. Ectopic expression of a mutant form of p53 in adult 
$\mathrm{GFAP}^{+}$cells suggests that, although NSCs are initially accumulating mutations, progenitors expressing Olig2, a marker of OPCs and TAPs, are actually expanding and forming tumors [161]. It will be interesting to determine how Numb and other ACD regulators may impact gliomagenesis through evasion of cell cycle control.

\section{Invasion and metastasis}

The molecular mechanisms leading to loss of polarity are still only partially understood. However, recent work has revealed that many important oncogenes act as key (mis)regulators of polarity. Given the frequency at which polarity defects are observed in human cancers, particularly in high-grade tumors, loss of polarity may be a necessary step during tumor progression. Epithelial mesenchymal transition (EMT) is thought to be an important source of invading and metastasizing cells (Fig. 6) [162]. Strikingly, recent work has shown that maintaining aPKC signaling at the apical surface is sufficient to prevent EMT in non-small cell lung carcinoma (NSCLC) cells in vitro [163].

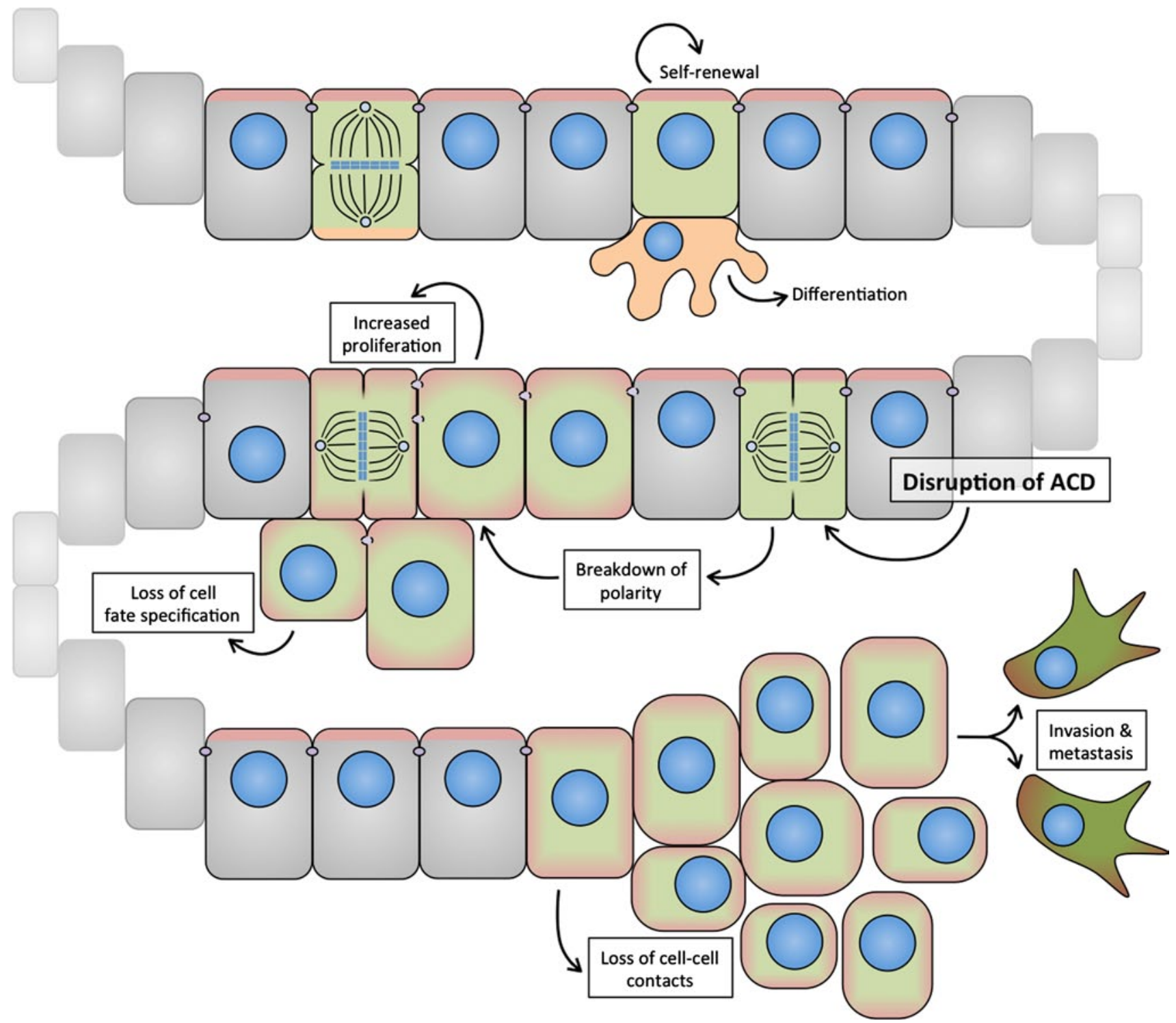

Fig. 6 Loss of polarity, ACD, and tissue architecture during EMT may contribute to invasion and metastasis. Apical (self-renewal, red) and basal (pro-differentiation, orange) signals are segregated to opposite compartments in asymmetric divisions of some epithelial progenitor cells (green). Disruption of ACD may lead to breakdown of polarity and increased inheritance of pro-proliferative signals usually confined to the apical domain, and a concomitant loss of cell-fate specification. Disruption of apical domain and AJ stability contribute to loss of epithelial integrity, and may be important steps in tumor cell invasion and metastasis 


\section{TGF- $\beta$ and polarity}

Transforming growth factor beta (TGF- $\beta$ ) signaling has long been implicated in EMT [164] and is frequently upregulated in tumor cells [165]. Recent studies have shown that TGF- $\beta$-mediated transformation involves direct disruption of epithelial cell polarity that precedes breakdown of AJs and epithelial organization. TGF- $\beta$ binding to the TGF- $\beta$ receptor III leads to direct phosphorylation of Par6 [166], via a partially aPKC-dependent mechanism [163]. Phosphorylation of Par6 leads to the breakdown of the Par complex, subsequent loss of apical G-protein activity, and breakdown of AJs $[163,167]$. Hypothetically, loss of polarity in epithelial cells could switch the plane of division from a perpendicular to a planar orientation. In a planar division, the apical domain is bisected and the cell divides symmetrically. In contrast, in a perpendicular division, the basal cell may no longer be bound to the epithelium and can acquire distinct fate and migrate further basally. Whether this switch of division occurs and is involved in EMT remains to be tested (Fig. 6).

\section{RTK signaling and polarity}

Dysregulation of the EGFR family of RTKs is very common in many cancers, including astrocytoma and oligodendroglioma. In epithelial tissues, EGFR family members have been implicated in regulation of polarity, which is an essential component of ACD. Activation of ErbB2 [168] or EGFR [169], both EGFR family members, leads to increased activity of mitogen-activated protein kinase (MAPK) family members MEK and ERK via increased Ras activity. ErbB2-mediated transformation of mammary epithelial cells directly disrupts the Par3/Par6/aPKC complex and this disruption leads to a breakdown of cellular polarity and epithelial structure [170]. It appears that, at least in the case of ErbB2-mediated transformation, polarity defects do not arise secondary to increases in proliferation, but rather polarity pathways are directly targeted by the oncogenic transformation during very early stages of tumor formation.

Moreover, the archetypal tumor suppressor PTEN, which is a negative regulator of RTK signaling, has also been implicated in the maintenance of epithelial polarity. Polarized localization of PTEN to the apical membrane dephosphorylates phosphatidylinositol 3,4,5-trisphosphate (PIP3), antagonizing phosphatidylinositol 3-kinase (PI3K) signaling at the apical domain of the cell. This restriction of PI3K activity at the apical surface appears to play a key role in establishing polarity, as localization of PTEN to the baso-lateral membrane results in the recruitment of apical protein $\mathrm{Cdc} 42$ to the lateral wall, while ablation of PTEN activity disrupts apical polarity [171].
Polarity complex and adherens junction breakdown

There is an intimate relationship between polarity and maintenance of AJs. Indeed, loss of Par3, Par6, or Cdc42 individually destabilize tight junctions, leading to disruption of epithelial polarity [172-175]. Studies of polarity in tumor initiation have suggested that disruption of normal epithelial organization may have cell type-specific, possibly opposite, effects on tumor initiation and progression. Loss of Par3 disrupts polarity is skin epithelia, and inhibits the initiation and progression of low-grade papilloma while promoting the development of high-grade keratoacanthomas [150]. Increased invasion following loss of Par3 may result from the induction of aPKC-dependent activation of JAK/STAT signaling, which induces metallopeptidase 9 (MMP9) expression by transformed mammary epithelial cells [149]. In a transplantation model of mammary carcinoma, loss of Par3 cooperates with ErbB2 to destabilize E-cadherin junctions and aberrantly activate Tiam1Rac-GTP signaling. Par3 loss also induces invasive behavior and metastases formation in this model. Loss of Par3, however, does not alter the weight of the primary tumor and fails to induce molecular changes associated with EMT [172]. Thus, loss of polarity may increase invasiveness by upregulating expression of extracellular matrix degrading enzymes as well as by disrupting inhibitory cell-cell contacts.

The temporal regulation of polarity defects and how they arise to impact tumor initiation and progression in human cancer is still unclear. In particular, the causal relationship between disruption of ACD and associated loss of cellular polarity is not yet known.

\section{Clinical relevance of ACD in tumor-propagating cells}

Glioblastoma multiforme (GBM) are fast-growing grade IV astrocytomas and extremely resistant to radiation- and chemotherapy. Oligodendrogliomas, on the other hand, are slow-growing cancers that are very responsive to chemotherapy [3, 146]. Yet, both tumors can arise from immature neural progenitors. These wide-ranging clinical manifestations in tumors with relative similar cellular origin provide an interesting conundrum. GEMM studies have provided evidence that astrocytomas originate from NSCs and OPCs [176, 177], whereas oligodendrogliomas originate from OPCs [146] (Fig. 5). OPCs are more sensitive than NSC to the growth inhibitory effects of temozolomide, an alkylating agent that is used as standard treatment for high-grade gliomas [146]. It is therefore speculated that the cellular origin of the two types of glioma (i.e., NSCs in GBM and OPCs in oligodendroglioma) in part determines their distinct therapy responses [178]. 
At least two models attempt to explain how a single cell of origin can lead to a heterogeneous tumor, displaying expression of markers of distinct brain cell types at various stages of differentiation. The stochastic model has long been established and claims that cancer cells acquire mutations stochastically and those mutations that provide a survival benefit will expand the affected cell population. In this model, cancer evolves from a single mutated cell (clone), through clonal expansions. On the other hand, the cancer stem cell (CSC) model postulates that only some cancer cells, namely those with stem cell properties, are tumorigenic. These CSCs are proposed to generate cellular hierarchies similar to NSCs by self-renewing and giving rise to progeny that then "differentiates" into heterogeneous tumor cells. Recently, an extended model of cancer development has been provided, which combines the stochastic and the CSC hypothesis by claiming that different cancer cell populations may evolve and these interact with each other and with the cancer microenvironment, thereby promoting cancer growth and development of therapy-resistant subpopulations [179]. Several studies have indeed provided evidence that diverse human cancers contain cellular subpopulations that exhibit stem-like features, such as multipotentiality and self-renewal ability. However, in contrast to their non-neoplastic counterparts, in CSCs the self-renewal machinery is dysregulated, leading to uncontrolled growth and heightened malignant potential when compared to the bulk of tumor cells [180]. Due to their ability to re-grow tumors with parental phenotypes when xenotransplantated into immunocompromised mice, these cells are also often called "tumor-propagating cells" (TPCs), tumor-initiating cells, or stem-like cancer cells. TPCs include the classically defined stem-like CSCs, as well as those tumor cells with heightened malignant capacity that share more attributes with lineage-restricted progenitor cells rather than stem cells.

CSCs are common in anaplastic astrocytoma and GBM [181-183] and are present in some anaplastic, high-grade oligodendrogliomas [184]. CSCs have been associated with therapy resistance to radiation $[185,186]$ and conventional chemotherapy [187, 188]. This has led to the speculation that while the majority of tumor cells are eliminated by conventional treatment, the CSCs survive to re-grow the tumor and are thus culprits for tumor recurrence. This model has been supported by a sophisticated study in a murine glioblastoma model, which showed that a relative quiescent $\mathrm{Nestin}^{+}$neural progenitor population survives treatment with the alkylating agent temozolomide, while the tumor bulk shrinks. Moreover, the Nestin ${ }^{+}$population significantly contributes to tumor re-growth [189].

The resemblance to stem and progenitor cells by CSCs and some TPCs, respectively, has raised the question of whether they undergo ACDs. CD133 is a surface marker for CSCs in GBM [182] and cultured CD133 ${ }^{+}$ CSCs indeed asymmetrically segregate CD133 during mitosis [6]. Molecular analyses have recently revealed that CD133 regulates CSC maintenance by activating the $\mathrm{PI} 3 \mathrm{~K} /$ Akt signaling pathway, which is frequently upregulated in glioma. CD133 physically interacts with the PI3K regulatory subunit $\mathrm{p} 85$ and thereby activates Akt signaling, promoting CSC self-renewal and tumor-initiating potential [190]. The cell-fate determinant Numb has been reported to asymmetrically segregate to $\mathrm{CD} 133^{\text {high }}$ expressing GBM cells and to specify their stem cell fate [191]. Interestingly, when oligodendroglioma cells were fractionated into stem cell-like and progenitor-like subpopulations, the progenitor-like subpopulation, characterized by high expression of the OPC marker NG2, but not the stem cell-like population, was capable of initiating tumor growth upon orthotopic implantation [146]. This indicates that oligodendroglioma harbor a population with progenitor-like features, rather than stem cell-features. We therefore call these cells TPCs rather than CSCs. It is feasible that a progenitor-like TPC has limited self-renewal potential and may eventually differentiate, which may explain the slower tumor growth of oligodendroglioma. Examination of $\mathrm{NG}^{+}$TPCs isolated from human surgical glioma specimens from patients prior to treatment revealed that these cells divide predominantly symmetrically [3]. Thus, asymmetry-defective oligodendroglioma TPCs presumably expand the tumor by non-hierarchical, symmetric divisions.

A major open question with regards to glioma CSCs and TPCs and in relation to cell division modes is about their predecessor in humans. Do CSCs have a common predecessor, such as a NSC, and do TPCs arise from progenitor cells instead? Such a direct lineage relationship of the CSCs and TPCs and their non-neoplastic counterpart is suggested by their biological similarities. Indeed, studies with GEMMs of glioma have suggested that NSCs can act as cellular origin of astrocytoma [176, 192]. Alternatively, CSCs may arise de novo by de-differentiation of, for example, OPC-like cells, which is further supported by the observation that high-grade astrocytoma can arise from $\mathrm{NG}^{+}$OPCs [177] and even from mature astrocytes [193]. These studies suggest that depending on cellular context and the nature of the mutations, several cell types have the capacity to give rise to CSCs and TPCs. Given that TPCs can divide asymmetrically [6], but astrocytes for example divide mostly symmetrically [120], these data indirectly suggest that a subset of tumor cells may acquire asymmetric division modes.

In summary, in glioma, the capacity for tumor propagation is not restricted to NSC-like cells, but can also be kept by progenitor-like cells, which are more accurately referred to as TPCs. Regardless of how these distinct phenotypes 
are acquired, it is clear that tumors are comprised of multiple cellular populations that may not be equally impacted by conventional therapies. Understanding why some populations of cells acquire and/or retain $\mathrm{ACD}$, while others expand symmetrically, may prove useful in understanding why distinct cancer cell types are unequally affected by treatment.

\section{Concluding remarks}

Groundbreaking work in Drosophila has helped to uncover many of the molecular mechanisms and cellular processes underlying ACD regulation in mammalian cells. Recent questions have begun to push the limits of invertebrate model systems, in particular with respect to the great variety of progenitor cell types and ACD mechanisms present in mammals.

As evidence mounts for adult progenitor cells as a likely cellular origin of distinct human cancers, the importance of understanding the molecular mechanisms underlying ACD regulation in different types of progenitor cells become more urgent. In-depth cellular analyses of complex and difficult-to-treat tumors, such as high-grade astrocytoma, constantly reveal new types of subpopulations that may be resistant to traditional therapy. New research will allow therapeutics to target defects in ACD, and associated changes in polarity, spindle orientation, and cell-fate decision, in different types of cancer cells.

Acknowledgments Research in the Petritsch lab is supported by the National Cancer Institute and National Institute of Neurological Disorders and Stroke of the National Institutes of Health under award numbers R01CA164746 and R01NS080619 (C.P.). The content of this publication is solely the responsibility of the authors and does not necessarily represent the official views of the National Institutes of Health. S.G.L. is supported by a CONACyT postdoctoral fellowship.

Open Access This article is distributed under the terms of the Creative Commons Attribution License which permits any use, distribution, and reproduction in any medium, provided the original author(s) and the source are credited.

\section{References}

1. Morrison SJ, Kimble J (2006) Asymmetric and symmetric stem-cell divisions in development and cancer. Nature 441:1068-1074. doi:10.1038/nature04956

2. Noctor SC, Martínez-Cerdeño V, Ivic L et al (2004) Cortical neurons arise in symmetric and asymmetric division zones and migrate through specific phases. Nat Neurosci 7:136-144. doi: $10.1038 / \mathrm{nn} 1172$

3. Sugiarto S, Persson AI, Munoz EG et al (2011) Asymmetrydefective oligodendrocyte progenitors are glioma precursors. Cancer Cell 20:328-340. doi:10.1016/j.ccr.2011.08.011

4. Wu M, Kwon HY, Rattis F et al (2007) Imaging hematopoietic precursor division in real time. Cell Stem Cell 1:541-554. doi:10.1016/j.stem.2007.08.009
5. Cicalese A, Bonizzi G, Pasi CE et al (2009) The tumor suppressor p53 regulates polarity of self-renewing divisions in mammary stem cells. Cell 138:1083-1095. doi:10.1016/j.cell.2009.06.048

6. Lathia JD, Hitomi M, Gallagher J et al (2011) Distribution of CD133 reveals glioma stem cells self-renew through symmetric and asymmetric cell divisions. Cell Death Dis 2:e200. doi:10.10 38/cddis. 2011.80

7. Knoblich JA (2010) Asymmetric cell division: recent developments and their implications for tumour biology. Nat Rev Mol Cell Biol 11:849-860. doi:10.1038/nrm3010

8. Bello BC, Izergina N, Caussinus E, Reichert H (2008) Amplification of neural stem cell proliferation by intermediate progenitor cells in Drosophila brain development. Neural Dev 3:5. doi:10.1186/1749-8104-3-5

9. Boone JQ, Doe CQ (2008) Identification of Drosophila type II neuroblast lineages containing transit amplifying ganglion mother cells. Dev Neurobiol 68:1185-1195. doi:10.1002/dneu.20648

10. Bowman SK, Rolland V, Betschinger J et al (2008) The tumor suppressors Brat and Numb regulate transit-amplifying neuroblast lineages in Drosophila. Dev Cell 14:535-546. doi:10.1016/ j.devcel.2008.03.004

11. Schaefer M, Shevchenko A, Knoblich JA (2000) A protein complex containing Inscuteable and the Galpha-binding protein Pins orients asymmetric cell divisions in Drosophila. Curr Biol $10: 353-362$

12. Atwood SX, Chabu C, Penkert RR et al (2007) Cdc42 acts downstream of Bazooka to regulate neuroblast polarity through Par-6 aPKC. J Cell Sci 120:3200-3206. doi:10.1242/jcs.014902

13. Peterson FC, Penkert RR, Volkman BF, Prehoda KE (2004) Cdc42 regulates the Par-6 PDZ domain through an allosteric CRIB-PDZ transition. Mol Cell 13:665-676

14. Wodarz A, Ramrath A (2000) Drosophila atypical protein kinase $\mathrm{C}$ associates with Bazooka and controls polarity of epithelia and neuroblasts. J Cell Biol 150:1361-1374

15. Willard FS, Kimple RJ, Siderovski DP (2004) Return of the GDI: the GoLoco motif in cell Division. Annu Rev Biochem 73:925-951

16. Yu F, Wang H, Qian $\mathrm{H}$ et al (2005) Locomotion defects, together with Pins, regulates heterotrimeric G-protein signaling during Drosophila neuroblast asymmetric divisions. Genes Dev 19:1341-1353. doi:10.1101/gad.1295505.eration

17. Ogawa H, Ohta N, Moon W, Matsuzaki F (2009) Protein phosphatase $2 \mathrm{~A}$ negatively regulates aPKC signaling by modulating phosphorylation of Par-6 in Drosophila neuroblast asymmetric divisions. J Cell Sci 122:3242-3249. doi:10.1242/jcs.050955

18. Wirtz-Peitz F, Nishimura T, Knoblich JA (2008) Linking cell cycle to asymmetric division: Aurora-A phosphorylates the Par complex to regulate Numb localization. Cell 135:161-173. doi:10.1016/j.cell.2008.07.049

19. Chabu C, Doe CQ (2009) Twins/PP2A regulates aPKC to control neuroblast cell polarity and self-renewal. Dev Biol 330:399-405. doi:10.1016/j.ydbio.2009.04.014

20. Wang C, Chang KC, Somers G et al (2009) Protein phosphatase 2A regulates self-renewal of Drosophila neural stem cells. Development 136:2287-2296. doi:10.1242/dev.035758

21. Krahn MP, Egger-Adam D, Wodarz A (2009) PP2A antagonizes phosphorylation of Bazooka by PAR-1 to control apical-basal polarity in dividing embryonic neuroblasts. Dev Cell 16:901908. doi:10.1016/j.devcel.2009.04.011

22. Januschke J, Llamazares S, Reina J, Gonzalez C (2011) Drosophila neuroblasts retain the daughter centrosome. Nat Commun 2:243. doi: $10.1038 /$ ncomms 1245

23. Rebollo E, Sampaio P, Januschke J et al (2007) Functionally unequal centrosomes drive spindle orientation in asymmetrically dividing Drosophila neural stem cells. Dev Cell 12:467474. doi:10.1016/j.devcel.2007.01.021 
24. Siller KH, Doe CQ (2009) Spindle orientation during asymmetric cell division. Nat Cell Biol 11:365-374. doi:10.1038/ ncb0409-365

25. Izumi Y, Ohta N, Hisata K et al (2006) Drosophila Pins-binding protein Mud regulates spindle-polarity coupling and centrosome organization. Nat Cell Biol 8:586-593. doi:10.1038/ ncb1409

26. Siller KH, Cabernard C, Doe CQ (2006) The NuMA-related Mud protein binds Pins and regulates spindle orientation in Drosophila neuroblasts. Nat Biotechnol 8:594-600. doi:10.1038/ncb1412

27. Bowman SK, Neumüller RA, Novatchkova M et al (2006) The Drosophila NuMA Homolog Mud regulates spindle orientation in asymmetric cell division. Dev Cell 10:731-742. doi:10.1016/j.devcel.2006.05.005

28. Siegrist SE, Doe CQ (2005) Microtubule-induced Pins/Galphai cortical polarity in Drosophila neuroblasts. Cell 123:13231335. doi:10.1016/j.cell.2005.09.043

29. Siegrist SE, Doe CQ (2007) Microtubule-induced cortical cell polarity. Genes Dev 21:483-496. doi:10.1101/gad.1511207

30. Wang H, Ouyang Y, Somers WG et al (2007) Polo inhibits progenitor self-renewal and regulates Numb asymmetry by phosphorylating Pon. Nature 449:96-100. doi:10.1038/nature06056

31. Wang H, Somers GW, Bashirullah A et al (2006) Aurora-A acts as a tumor suppressor and regulates self-renewal of Drosophila neuroblasts. Genes Dev 20:3453-3463. doi:10.1101/ gad.1487506

32. Lee C-Y, Andersen RO, Cabernard C et al (2006) Drosophila Aurora-A kinase inhibits neuroblast self-renewal by regulating aPKC/Numb cortical polarity and spindle orientation. Genes Dev 20:3464-3474. doi:10.1101/gad.1489406

33. Kraut R, Chia W, Jan LY et al (1996) Role of inscuteable in orienting asymmetric cell divisions in Drosophila. Nature 383:5055. doi:10.1038/383050a0

34. Petritsch C, Tavosanis G, Turck CW et al (2003) The Drosophila myosin VI Jaguar is required for basal protein targeting and correct spindle orientation in mitotic neuroblasts. Dev Cell 4:273-281

35. Betschinger J, Mechtler K, Knoblich JJA (2003) The Par complex directs asymmetric cell division by phosphorylating the cytoskeletal protein Lgl. Nature 422:326-330. doi:10.1038/ nature 01486

36. Smith CA, Lau KM, Rahmani $\mathrm{Z}$ et al (2007) aPKC-mediated phosphorylation regulates asymmetric membrane localization of the cell fate determinant Numb. EMBO J 26:468-480. doi:10 .1038/sj.emboj.7601495

37. Lu B, Rothenberg M, Jan LY, Jan YN (1998) Partner of Numb colocalizes with Numb during mitosis and directs Numb asymmetric localization in Drosophila neural and muscle progenitors. Cell 95:225-235

38. Atwood SX, Prehoda KE (2009) aPKC phosphorylates Miranda to polarize fate determinants during neuroblast asymmetric cell division. Curr Biol 19:723-729. doi:10.1016/j.cub.2009.03.056

39. Shen CP, Jan LY, Jan YN (1997) Miranda is required for the asymmetric localization of Prospero during mitosis in Drosophila. Cell 90:449-458

40. Ikeshima-Kataoka H, Skeath JB, Nabeshima Y et al (1997) Miranda directs Prospero to a daughter cell during Drosophila asymmetric divisions. Nature 390:625-629. doi:10.1038/37641

41. Shen CP, Knoblich JA, Chan YM et al (1998) Miranda as a multidomain adapter linking apically localized Inscuteable and basally localized Staufen and Prospero during asymmetric cell division in Drosophila. Genes Dev 12:1837-1846

42. Matsuzaki F, Ohshiro T, Ikeshima-Kataoka H, Izumi H (1998) Miranda localizes staufen and prospero asymmetrically in mitotic neuroblasts and epithelial cells in early Drosophila embryogenesis. Development 125:4089-4098
43. Betschinger J, Mechtler K, Knoblich JA (2006) Asymmetric segregation of the tumor suppressor brat regulates selfrenewal in Drosophila neural stem cells. Cell 124:1241-1253. doi:10.1016/j.cell.2006.01.038

44. Lee C-Y, Wilkinson BD, Siegrist SE et al (2006) Brat is a Miranda cargo protein that promotes neuronal differentiation and inhibits neuroblast self-renewal. Dev Cell 10:441-449. doi:10.1016/j.devcel.2006.01.017

45. Li P, Yang X, Wasser M et al (1997) Inscuteable and Staufen mediate asymmetric localization and segregation of prospero RNA during Drosophila neuroblast cell divisions. Cell 90:437-447

46. Broadus J, Fuerstenberg S, Doe CQ (1998) Staufen-dependent localization of prospero mRNA contributes to neuroblast daughter-cell fate. Nature 391:792-795. doi:10.1038/35861

47. Chu-Lagraff Q, Wright DM, McNeil LK, Doe CQ (1991) The prospero gene encodes a divergent homeodomain protein that controls neuronal identity in Drosophila. Development 2:79-85

48. Doe CQ, Chu-LaGraff Q, Wright DM, Scott MP (1991) The prospero gene specifies cell fates in the Drosophila central nervous system. Cell 65:451-464

49. Choksi SP, Southall TD, Bossing T et al (2006) Prospero acts as a binary switch between self-renewal and differentiation in Drosophila neural stem cells. Dev Cell 11:775-789. doi:10.1016/j.devcel.2006.09.015

50. Bello B, Reichert H, Hirth F (2006) The brain tumor gene negatively regulates neural progenitor cell proliferation in the larval central brain of Drosophila. Development 133:2639-2648. doi:10.1242/dev.02429

51. Qian X, Goderie SK, Shen Q et al (1998) Intrinsic programs of patterned cell lineages in isolated vertebrate CNS ventricular zone cells. Development 125:3143-3152

52. Qian X, Shen Q, Goderie SK et al (2000) Timing of CNS cell generation: a programmed sequence of neuron and glial cell production from isolated murine cortical stem cells. Neuron 28:69-80

53. Aaku-Saraste E, Hellwig A, Huttner WB (1996) Loss of occludin and functional tight junctions, but not $\mathrm{ZO}-1$, during neural tube closure-remodeling of the neuroepithelium prior to neurogenesis. Dev Biol 180:664-679. doi:10.1006/dbio.1996.0336

54. Zhadanov AB, Provance DW, Speer CA et al (1999) Absence of the tight junctional protein AF-6 disrupts epithelial cell-cell junctions and cell polarity during mouse development. Curr Biol 9:880-888

55. Noctor SC, Martínez-Cerdeño V, Kriegstein AR (2008) Distinct behaviors of neural stem and progenitor cells underlie cortical neurogenesis. J Comput Neurol 508:28-44. doi:10.1002/cne.21669

56. Miyata T, Kawaguchi A, Saito K et al (2004) Asymmetric production of surface-dividing and non-surface-dividing cortical progenitor cells. Development 131:3133-3145. doi:10.1242/dev.01173

57. Gal JS, Morozov YM, Ayoub AE et al (2006) Molecular and morphological heterogeneity of neural precursors in the mouse neocortical proliferative zones. J Neurosci 26:1045-1056. doi:1 0.1523/JNEUROSCI.4499-05.2006

58. Hansen DV, Lui JH, Parker PRL, Kriegstein AR (2010) Neurogenic radial glia in the outer subventricular zone of human neocortex. Nature 464:554-561

59. Fietz SA, Kelava I, Vogt J et al (2010) OSVZ progenitors of human and ferret neocortex are epithelial-like and expand by integrin signaling. Nat Neurosci 13:690-699. doi:10.1038/nn.2553

60. Wang X, Tsai J-W, LaMonica B, Kriegstein AR (2011) A new subtype of progenitor cell in the mouse embryonic neocortex. Nat Neurosci 14:555-561. doi:10.1038/nn.2807

61. Shitamukai A, Konno D, Matsuzaki F (2011) Oblique radial glial divisions in the developing mouse neocortex induce selfrenewing progenitors outside the germinal zone that resemble 
primate outer subventricular zone progenitors. J Neurosci 31:3683-3695. doi:10.1523/JNEUROSCI.4773-10.2011

62. Manabe N, Hirai S-I, Imai F et al (2002) Association of ASIP/mPAR-3 with adherens junctions of mouse neuroepithelial cells. Dev Dyn 225:61-69. doi:10.1002/dvdy.10139

63. Cappello S, Attardo A, Wu X et al (2006) The Rho-GTPase cdc42 regulates neural progenitor fate at the apical surface. Nat Neurosci 9:1099-1107. doi:10.1038/nn1744

64. Chen L, Liao G, Yang L et al (2006) Cdc42 deficiency causes Sonic hedgehog-independent holoprosencephaly. Proc Natl Acad Sci USA 103:16520-16525. doi:10.1073/pnas.0603533103

65. Imai $F$ (2006) Inactivation of aPKC results in the loss of adherens junctions in neuroepithelial cells without affecting neurogenesis in mouse neocortex. Development 133:1855. doi:10.1242/dev.02389

66. Marthiens V, ffrench-Constant C (2009) Adherens junction domains are split by asymmetric division of embryonic neural stem cells. EMBO Rep 10:515-520. doi:10.1038/em bor.2009.36

67. Kosodo Y, Röper K, Haubensak W et al (2004) Asymmetric distribution of the apical plasma membrane during neurogenic divisions of mammalian neuroepithelial cells. EMBO J 23:2314-2324. doi:10.1038/sj.emboj.7600223

68. Sykes AM, Huttner WB (2013) Prominin-1 (CD133) and the cell biology of neural progenitors and their progeny. Adv Exp Med Biol 777:89-98. doi:10.1007/978-1-4614-5894-4_6

69. Bauer N, Fonseca A-V, Florek M et al (2008) New insights into the cell biology of hematopoietic progenitors by studying prominin-1 (CD133). Cells Tissues Organs 188:127-138. doi: $10.1159 / 000112847$

70. Zacchigna $\mathrm{S}, \mathrm{Oh} \mathrm{H}$, Wilsch-Bräuninger $\mathrm{M}$ et al (2009) Loss of the cholesterol-binding protein prominin-1/CD133 causes disk dysmorphogenesis and photoreceptor degeneration. J Neurosci 29:2297-2308. doi:10.1523/JNEUROSCI.2034-08.2009

71. Bultje RS, Castaneda-Castellanos DR, Jan LY et al (2009) Mammalian Par3 regulates progenitor cell asymmetric division via notch signaling in the developing neocortex. Neuron 63:189-202. doi:10.1016/j.neuron.2009.07.004

72. Gaiano N, Nye JS, Fishell G (2000) Radial glial identity is promoted by Notch1 signaling in the murine forebrain. Neuron 26:395-404

73. Rasin M-R, Gazula V-R, Breunig JJ et al (2007) Numb and Numbl are required for maintenance of cadherin-based adhesion and polarity of neural progenitors. Nat Neurosci 10:819827. doi:10.1038/nn1924

74. Konno D, Shioi G, Shitamukai A et al (2008) Neuroepithelial progenitors undergo LGN-dependent planar divisions to maintain self-renewability during mammalian neurogenesis. Nat Cell Biol 10:93-101. doi:10.1038/ncb1673

75. Postiglione MP, Jüschke C, Xie Y et al (2011) Mouse inscuteable induces apical-basal spindle orientation to facilitate intermediate progenitor generation in the developing neocortex. Neuron 72:269-284. doi:10.1016/j.neuron.2011.09.022

76. Haydar TF, Ang E, Rakic P (2003) Mitotic spindle rotation and mode of cell division in the developing telencephalon. Proc Natl Acad Sci USA 100:2890-2895. doi:10.1073/pnas.0437969100

77. Du Q, Stukenberg PT, Macara IG (2001) A mammalian partner of inscuteable binds NuMA and regulates mitotic spindle organization. Nat Cell Biol 3:1069-1075. doi:10.1038/ncb1201-1069

78. Wang X, Lui J, Kriegstein A (2011) Orienting fate: spatial regulation of neurogenic divisions. Neuron 72:191-193

79. Wang X, Tsai J-W, Imai JH et al (2009) Asymmetric centrosome inheritance maintains neural progenitors in the neocortex. Nature 461:947-955. doi:10.1038/nature08435

80. Sakai D, Dixon J, Dixon MJ, Trainor PA (2012) Mammalian neurogenesis requires Treacle-Plk1 for precise control of spindle orientation, mitotic progression, and maintenance of neural progenitor cells. PLoS Genet 8:e1002566. doi:10.1371/ journal.pgen.1002566

81. Yamashita YM, Yuan H, Cheng J, Hunt AJ (2010) Polarity in stem cell division: asymmetric stem cell division in tissue homeostasis. CSH Perspect Biol 2:a001313. doi:10.1101/cshperspect. a001313

82. Vessey JP, Amadei G, Burns SE et al (2012) An asymmetrically localized staufen2-dependent RNA complex regulates maintenance of Mammalian neural stem cells. Cell Stem Cell 11:517528. doi:10.1016/j.stem.2012.06.010

83. Kusek G, Campbell M, Doyle F et al (2012) Asymmetric segregation of the double-stranded RNA binding protein Staufen2 during mammalian neural stem cell divisions promotes lineage progression. Cell Stem Cell 11:505-516. doi:10.1016/j. stem.2012.06.006

84. Dyer MA, Livesey FJ, Cepko CL, Oliver G (2003) Prox1 function controls progenitor cell proliferation and horizontal cell genesis in the mammalian retina. Nat Genet 34:53-58. doi:10.1038/ng1144

85. Schwamborn JC, Berezikov E, Knoblich JA (2009) The TRIMNHL protein TRIM32 activates microRNAs and prevents self-renewal in mouse neural progenitors. Cell 136:913-925. doi:10.1016/j.cell.2008.12.024

86. Sato T, Okumura F, Kano S et al (2011) TRIM32 promotes neural differentiation through retinoic acid receptor-mediated transcription. J Cell Sci 124:3492-3502. doi:10.1242/jcs.088799

87. Hillje A-L, Worlitzer MMA, Palm T, Schwamborn JC (2011) Neural stem cells maintain their stemness through protein kinase $\mathrm{C} \zeta$-mediated inhibition of TRIM32. Stem Cells 29:1437-1447. doi:10.1002/stem.687

88. Lange C, Huttner WB, Calegari F (2009) Cdk4/cyclinD1 overexpression in neural stem cells shortens G1, delays neurogenesis, and promotes the generation and expansion of basal progenitors. Cell Stem Cell 5:320-331. doi:10.1016/j.stem.2009.05.026

89. Lim S, Kaldis P (2012) Loss of Cdk2 and Cdk4 induces a switch from proliferation to differentiation in neural stem cells. Stem Cells 30:1509-1520. doi:10.1002/stem.1114

90. Tsunekawa Y, Britto JM, Takahashi M et al (2012) Cyclin D2 in the basal process of neural progenitors is linked to nonequivalent cell fates. EMBO J 31:1879-1892. doi:10.1038/em boj. 2012.43

91. Glickstein SB, Alexander S, Ross ME (2007) Differences in cyclin D2 and D1 protein expression distinguish forebrain progenitor subsets. Cereb Cortex 17:632-642. doi:10.1093/cercor/ bhk008

92. Glickstein SB, Monaghan JA, Koeller HB et al (2009) Cyclin D2 is critical for intermediate progenitor cell proliferation in the embryonic cortex. J Neurosci 29:9614-9624. doi:10.1523/JNE UROSCI.2284-09.2009

93. Voigt T (1989) Development of glial cells in the cerebral wall of ferrets: direct tracing of their transformation from radial glia into astrocytes. J Comput Neurol 289:74-88. doi:10.1002 /cne.902890106

94. Spassky N, Merkle FT, Flames N et al (2005) Adult ependymal cells are postmitotic and are derived from radial glial cells during embryogenesis. J Neurosci 25:10-18. doi:10.1523/JNEUR OSCI.1108-04.2005

95. Altman J (1969) Autoradiographic and histological studies of postnatal neurogenesis. IV. Cell proliferation and migration in the anterior forebrain, with special reference to persisting neurogenesis in the olfactory bulb. J Comput Neurol 137:433-457. doi: $10.1002 /$ cne. 901370404

96. Luskin MB (1993) Restricted proliferation and migration of postnatally generated neurons derived from the forebrain subventricular zone. Neuron 11:173-189 
97. Kaplan MS, Hinds JW (1977) Neurogenesis in the adult rat: electron microscopic analysis of light radioautographs. Science 197:1092-1094

98. Gage FH, Kempermann G, Palmer TD et al (1998) Multipotent progenitor cells in the adult dentate gyrus. J Neurobiol 36:249-266

99. Doetsch F, Caillé I, Lim DA et al (1999) Subventricular zone astrocytes are neural stem cells in the adult mammalian brain. Cell 97:703-716

100. Seri B, García-Verdugo JM, McEwen BS, Alvarez-Buylla A (2001) Astrocytes give rise to new neurons in the adult mammalian hippocampus. J Neurosci 21:7153-7160

101. Doetsch F, García-Verdugo JM, Alvarez-Buylla A (1997) Cellular composition and three-dimensional organization of the subventricular germinal zone in the adult mammalian brain. $\mathrm{J}$ Neurosci 17:5046-5061

102. Menn B, Garcia-Verdugo JM, Yaschine C et al (2006) Origin of oligodendrocytes in the subventricular zone of the adult brain. J Neurosci 26:7907-7918. doi:10.1523/JNEUROSCI. 1299-06.2006

103. Doetsch F, García-Verdugo JM, Alvarez-Buylla A (1999) Regeneration of a germinal layer in the adult mammalian brain. Proc Natl Acad Sci USA 96:11619-11624

104. Mirzadeh Z, Merkle FT, Soriano-Navarro M et al (2008) Neural stem cells confer unique pinwheel architecture to the ventricular surface in neurogenic regions of the adult brain. Cell Stem Cell 3:265-278. doi:10.1016/j.stem.2008.07.004

105. Kuo CT, Mirzadeh Z, Soriano-Navarro M et al (2006) Postnatal deletion of Numb/Numblike reveals repair and remodeling capacity in the subventricular neurogenic niche. Cell 127:12531264. doi:10.1016/j.cell.2006.10.041

106. Pastrana E, Cheng L-C, Doetsch F (2009) Simultaneous prospective purification of adult subventricular zone neural stem cells and their progeny. Proc Natl Acad Sci USA 106:63876392. doi:10.1073/pnas.0810407106

107. Ponti G, Obernier K, Guinto C et al (2013) Cell cycle and lineage progression of neural progenitors in the ventricularsubventricular zones of adult mice. Proc Natl Acad Sci USA 110:E1045-E1054. doi:10.1073/pnas.1219563110

108. Costa MR, Ortega F, Brill MS et al (2011) Continuous live imaging of adult neural stem cell division and lineage progression in vitro. Development 138:1057-1068. doi:10.1242/dev. 061663

109. Shen Q, Wang Y, Kokovay E et al (2008) Adult SVZ stem cells lie in a vascular niche: a quantitative analysis of niche cellcell interactions. Cell Stem Cell 3:289-300. doi:10.1016/j. stem.2008.07.026

110. Andreu-Agulló C, Morante-Redolat JM, Delgado AC, Fariñas I (2009) Vascular niche factor PEDF modulates Notch-dependent stemness in the adult subependymal zone. Nat Neurosci 12:1514-1523. doi:10.1038/nn.2437

111. Shen Q, Goderie SK, Jin L et al (2004) Endothelial cells stimulate self-renewal and expand neurogenesis of neural stem cells. Science 304:1338-1340

112. Lehtinen MK, Zappaterra MW, Chen X et al (2011) The cerebrospinal fluid provides a proliferative niche for neural progenitor cells. Neuron 69:893-905. doi:10.1016/j.neuron. 2011.01.023

113. Ferron SR, Pozo N, Laguna A et al (2010) Regulated segregation of kinase Dyrk1A during asymmetric neural stem cell division is critical for EGFR-mediated biased signaling. Cell Stem Cell 7:367-379. doi:10.1016/j.stem.2010.06.021

114. Sun Y, Goderie SK, Temple S (2005) Asymmetric distribution of EGFR receptor during mitosis generates diverse CNS progenitor cells. Neuron 45:873-886. doi:10.1016/j. neuron.2005.01.045
115. Bignami A, Eng LF, Dahl D, Uyeda CT (1972) Localization of the glial fibrillary acidic protein in astrocytes by immunofluorescence. Brain Res 43:429-435

116. Barry D, McDermott K (2005) Differentiation of radial glia from radial precursor cells and transformation into astrocytes in the developing rat spinal cord. Glia 50:187-197. doi:10.1002/ glia.20166

117. Hirano M, Goldman JE (1988) Gliogenesis in rat spinal cord: evidence for origin of astrocytes and oligodendrocytes from radial precursors. J Neurosci Res 21:155-167. doi:10.1002/ jnr.490210208

118. Malatesta P, Hartfuss E, Götz M (2000) Isolation of radial glial cells by fluorescent-activated cell sorting reveals a neuronal lineage. Development 127:5253-5263

119. Zhu X, Bergles DE, Nishiyama A (2008) NG2 cells generate both oligodendrocytes and gray matter astrocytes. Development 135:145-157. doi:10.1242/dev.004895

120. Ge W-PP, Miyawaki A, Gage FH et al (2012) Local generation of glia is a major astrocyte source in postnatal cortex. Nature 484:376-380. doi:10.1038/nature 10959

121. Pringle NP, Richardson WD (1993) A singularity of PDGF alpha-receptor expression in the dorsoventral axis of the neural tube may define the origin of the oligodendrocyte lineage. Development 117:525-533

122. Zhou Q, Wang S, Anderson DJ (2000) Identification of a novel family of oligodendrocyte lineage-specific basic helix-loophelix transcription factors. Neuron 25:331-343

123. Nishiyama A, Lin XH, Giese $\mathrm{N}$ et al (1996) Co-localization of NG2 proteoglycan and PDGF alpha-receptor on O2A progenitor cells in the developing rat brain. J Neurosci Res 43:299-314. doi: 10.1002/(SICI) 1097-4547(19960201)43:3<299:AIDJNR5 $>3.0 . \mathrm{CO} ; 2-\mathrm{E}$

124. Vallstedt A, Klos JM, Ericson J (2005) Multiple dorsoventral origins of oligodendrocyte generation in the spinal cord and hindbrain. Neuron 45:55-67. doi:10.1016/j.neuron.2004.12.026

125. Kessaris N, Fogarty M, Iannarelli P et al (2006) Competing waves of oligodendrocytes in the forebrain and postnatal elimination of an embryonic lineage. Nat Neurosci 9:173-179. doi: $10.1038 / \mathrm{nn} 1620$

126. Geha S, Pallud J, Junier M-P et al (2010) NG2+/Olig2+ cells are the major cycle-related cell population of the adult human normal brain. Brain Pathol 20:399-411. doi:10.1111/j.1750-3639.2009.00295.x

127. Psachoulia K, Jamen F, Young KM, Richardson WD (2009) Cell cycle dynamics of NG2 cells in the postnatal and ageing brain. Neuron Glia Biol 5:57-67. doi:10.1017/S1740925X09990354

128. Zhu X, Hill RA, Dietrich D et al (2011) Age-dependent fate and lineage restriction of single NG2 cells. Development 138:745753. doi:10.1242/dev.047951

129. Wade A, Robinson AE, Engler JR et al (2013) Proteoglycans and their roles in brain cancer. FEBS J. doi:10.1111/febs.12109

130. Hanahan D, Weinberg RA (2000) The hallmarks of cancer. Cell 100:57-70

131. Hanahan D, Weinberg RA (2011) Hallmarks of cancer: the next generation. Cell 144:646-674. doi:10.1016/j.cell.2011.02.013

132. Lee C-Y, Robinson KJ, Doe CQ (2006) Lgl, Pins and aPKC regulate neuroblast self-renewal versus differentiation. Nature 439:594-598. doi:10.1038/nature04299

133. Gateff E (1978) Malignant neoplasms of genetic origin in Drosophila melanogaster. Science 200:1448-1459

134. Caussinus E, Gonzalez C (2005) Induction of tumor growth by altered stem-cell asymmetric division in Drosophila melanogaster. Nat Genet 37:1125-1129

135. Zyss D, Gergely F (2009) Centrosome function in cancer: guilty or innocent? Trends Cell Biol 19:334-346. doi:10.1016/j.tcb.2009.04.001 
136. Castellanos E, Dominguez P, Gonzalez C (2008) Centrosome dysfunction in Drosophila neural stem cells causes tumors that are not due to genome instability. Curr Biol 18:1209-1214. doi:10.1016/j.cub.2008.07.029

137. Basto R, Brunk K, Vinadogrova $T$ et al (2008) Centrosome amplification can initiate tumorigenesis in flies. Cell 133:1032-1042

138. Read RD (2011) Drosophila melanogaster as a model system for human brain cancers. Glia 59:1364-1376. doi:10.1002/ glia. 21148

139. Vogelstein B, Kinzler KW (2002) The genetic basis of human cancer. McGraw Hill, Toronto

140. Kunnev D, Ivanov I, Ionov Y (2009) Par-3 partitioning defective 3 homolog (C. elegans) and androgen-induced prostate proliferative shutoff associated protein genes are mutationally inactivated in prostate cancer cells. BMC Cancer 9:318. doi:10.1186/1471-2407-9-318

141. Rothenberg SM, Mohapatra G, Rivera MN et al (2010) A genome-wide screen for microdeletions reveals disruption of polarity complex genes in diverse human cancers. Cancer Res 70:2158-2164. doi:10.1158/0008-5472.CAN-09-3458

142. TCGA (2008) Comprehensive genomic characterization defines human glioblastoma genes and core pathways. Nature 455:1061-1068. doi:10.1038/nature07385

143. Furnari FB, Fenton T, Bachoo RM et al (2007) Malignant astrocytic glioma: genetics, biology, and paths to treatment. Genes Dev 21:2683-2710. doi:10.1101/gad.1596707

144. Chen J, McKay RM, Parada LF (2012) Malignant glioma: lessons from genomics, mouse models, and stem cells. Cell 149:36-47. doi:10.1016/j.cell.2012.03.009

145. Weiss WA, Burns MJ, Hackett C et al (2003) Genetic determinants of malignancy in a mouse model for oligodendroglioma. Cancer Res 63:1589-1595

146. Persson AI, Petritsch C, Swartling FJ et al (2010) Non-stem cell origin for oligodendroglioma. Cancer Cell 18:669-682. doi:10.1016/j.ccr.2010.10.033

147. Klezovitch O, Fernandez TE, Tapscott SJ, Vasioukhin V (2004) Loss of cell polarity causes severe brain dysplasia in Lg11 knockout mice. Genes Dev 18:559-571. doi:10.1101/ gad.1178004

148. McCaffrey LM, Macara IG (2009) The Par3/aPKC interaction is essential for end bud remodeling and progenitor differentiation during mammary gland morphogenesis. Genes Dev 23:1450-1460. doi:10.1101/gad.1795909

149. McCaffrey LM, Montalbano J, Mihai C, Macara IG (2012) Loss of the Par3 polarity protein promotes breast tumorigenesis and metastasis. Cancer Cell 22:601-614. doi:10.1016/j.ccr.2012.10.003

150. Iden S, Riel WE, Schäfer R et al (2012) Tumor type-dependent function of the par3 polarity protein in skin tumorigenesis. Cancer Cell 22:389-403. doi:10.1016/j.ccr.2012.08.004

151. Pece S, Serresi M, Santolini E et al (2004) Loss of negative regulation by Numb over Notch is relevant to human breast carcinogenesis. J Cell Biol 167:215-221. doi:10.1083/ jcb. 200406140

152. Colaluca IN, Tosoni D, Nuciforo P et al (2008) NUMB controls p53 tumour suppressor activity. Nature 451:76-80. doi:10.1038/ nature 06412

153. Ito T, Kwon HY, Zimdahl B et al (2010) Regulation of myeloid leukaemia by the cell-fate determinant Musashi. Nature 466:765-768. doi:10.1038/nature09171

154. Duncan AW, Rattis FM, DiMascio LN et al (2005) Integration of Notch and Wnt signaling in hematopoietic stem cell maintenance. Nat Immunol 6:314-322. doi:10.1038/ni1164

155. Kharas MG, Lengner CJ, Al-Shahrour F et al (2010) Musashi-2 regulates normal hematopoiesis and promotes aggressive myeloid leukemia. Nat Med 16:903-908. doi:10.1038/nm.2187
156. Okabe M, Imai T, Kurusu M et al (2001) Translational repression determines a neuronal potential in Drosophila asymmetric cell division. Nature 411:94-98. doi:10.1038/35075094

157. Sakakibara S, Imai T, Hamaguchi K et al (1996) MouseMusashi-1, a neural RNA-binding protein highly enriched in the mammalian CNS stem cell. Dev Biol 176:230-242

158. Imai $T$, Tokunaga $A$, Yoshida $T$ et al (2001) The neural RNAbinding protein Musashi1 translationally regulates mammalian numb gene expression by interacting with its mRNA. Mol Cell Biol 21:3888-3900. doi:10.1128/MCB.21.12.3888-3900.2001

159. Gil-Perotin S, Marin-Husstege M, Li J et al (2006) Loss of p53 induces changes in the behavior of subventricular zone cells: implication for the genesis of glial tumors. J Neurosci 26:11071116. doi:10.1523/JNEUROSCI.3970-05.2006

160. Zheng H, Ying H, Yan $\mathrm{H}$ et al (2008) p53 and Pten control neural and glioma stem/progenitor cell renewal and differentiation. Nature 455:1129-1133. doi:10.1038/nature07443

161. Wang Y, Yang J, Zheng H et al (2009) Expression of mutant p53 proteins implicates a lineage relationship between neural stem cells and malignant astrocytic glioma in a murine model. Cancer Cell 15:514-526. doi:10.1016/j.ccr.2009.04.001

162. Kalluri R, Weinberg RA (2009) The basics of epithelial-mesenchymal transition. J Clin Invest 119:1420-1428. doi:10.1172/JCI39104

163. Gunaratne A, Thai BL, Guglielmo GM (2012) Atypical PKC phosphorylates Par6 and facilitates TGF 3 -induced EMT. Mol Cell Biol. doi:10.1128/MCB.00837-12

164. Oft M, Peli J, Rudaz C et al (1996) TGF-beta1 and Ha-Ras collaborate in modulating the phenotypic plasticity and invasiveness of epithelial tumor cells. Genes Dev 10:2462-2477

165. Huber MA, Kraut N, Beug H (2005) Molecular requirements for epithelial-mesenchymal transition during tumor progression. Curr Opin Cell Biol 17:548-558. doi:10.1016/j.ceb.2005.08.001

166. Viloria-Petit AM, David L, Jia JY et al (2009) A role for the TGFbeta-Par6 polarity pathway in breast cancer progression. Proc Natl Acad Sci USA 106:14028-14033. doi:10.1073/p nas.0906796106

167. Hills CE, Siamantouras E, Smith SW et al (2012) TGF $\beta$ modulates cell-to-cell communication in early epithelial-to-mesenchymal transition. Diabetologia 55:812-824. doi:10.1007/ s00125-011-2409-9

168. Murray NR, Jamieson L, Yu W et al (2004) Protein kinase Ciota is required for Ras transformation and colon carcinogenesis in vivo. J Cell Biol 164:797-802. doi:10.1083/jcb.200311011

169. Cohen EEW, Lingen MW, Zhu B et al (2006) Protein kinase C zeta mediates epidermal growth factor-induced growth of head and neck tumor cells by regulating mitogen-activated protein kinase. Cancer Res 66:6296-6303. doi:10.1158/0008-5472. CAN-05-3139

170. Aranda V, Haire T, Nolan ME et al (2006) Par6-aPKC uncouples ErbB2 induced disruption of polarized epithelial organization from proliferation control. Nat Cell Biol 8:1235-1245. doi: $10.1038 /$ ncb1485

171. Martin-Belmonte F, Gassama A, Datta A et al (2007) PTENmediated apical segregation of phosphoinositides controls epithelial morphogenesis through Cdc42. Cell 128:383-397. doi:10.1016/j.cell.2006.11.051

172. Xue B, Krishnamurthy K, Allred DC, Muthuswamy SK (2012) Loss of Par3 promotes breast cancer metastasis by compromising cell-cell cohesion. Nat Cell Biol 15:1-14. doi:10.1038/ncb2663

173. Cunliffe HE, Jiang Y, Fornace KM et al (2012) PAR6B is required for tight junction formation and activated $\mathrm{PKC} \zeta$ localization in breast cancer. Am J Cancer Res 2:478-491

174. Tomaić V, Gardiol D, Massimi P et al (2009) Human and primate tumour viruses use PDZ binding as an evolutionarily conserved mechanism of targeting cell polarity regulators. Oncogene 28:1-8. doi:10.1038/onc.2008.365 
175. Sipes NS, Feng Y, Guo F et al (2011) Cdc42 regulates extracellular matrix remodeling in three dimensions. J Biol Chem 286:36469-36477. doi:10.1074/jbc.M111.283176

176. Alcantara Llaguno S, Chen J, Kwon C-H et al (2009) Malignant astrocytomas originate from neural stem/progenitor cells in a somatic tumor suppressor mouse model. Cancer Cell 15:45-56. doi:10.1016/j.ccr.2008.12.006

177. Liu C, Sage JC, Miller MR et al (2011) Mosaic analysis with double markers reveals tumor cell of origin in glioma. Cell 146:209-221. doi:10.1016/j.cell.2011.06.014

178. Pei Y, Wechsler-Reya RJ (2010) A malignant oligarchy: progenitors govern the behavior of oligodendrogliomas. Cancer Cell 18:546-547. doi:10.1016/j.ccr.2010.11.031

179. Bonavia R, Inda M-M, Cavenee WK, Furnari FB (2011) Heterogeneity maintenance in glioblastoma: a social network. Cancer Res 71:4055-4060. doi:10.1158/0008-5472.CAN-11-0153

180. Visvader JE, Lindeman GJ (2008) Cancer stem cells in solid tumours: accumulating evidence and unresolved questions. Nat Rev Cancer 8:755-768. doi:10.1038/nrc2499

181. Singh SK, Clarke ID, Terasaki $M$ et al (2003) Identification of a cancer stem cell in human brain tumors. Cancer Res 63:5821-5828

182. Singh SK, Hawkins C, Clarke ID et al (2004) Identification of human brain tumour initiating cells. Nature 432:396-401. doi:10.1038/nature03128

183. Hemmati HD, Nakano I, Lazareff JA et al (2003) Cancerous stem cells can arise from pediatric brain tumors. Proc Natl Acad Sci USA 100:15178-15183. doi:10.1073/pnas.2036535100

184. Kelly JJ, Blough MD, Stechishin OD et al (2010) Oligodendroglioma cell lines containing $\mathrm{t}(1 ; 19)(\mathrm{q} 10 ; \mathrm{p} 10)$. Neuro Oncol 12:745-755. doi:10.1093/neuonc/noq031

185. Bao S, Wu Q, McLendon RE et al (2006) Glioma stem cells promote radioresistance by preferential activation of the DNA damage response. Nature 444:756-760. doi:10.1038/ nature 05236

186. Tamura K, Aoyagi M, Wakimoto H et al (2010) Accumulation of CD133-positive glioma cells after high-dose irradiation by Gamma knife surgery plus external beam radiation. J Neurosurg 113:310-318. doi:10.3171/2010.2.JNS091607

187. Li X, Lewis MT, Huang J et al (2008) Intrinsic resistance of tumorigenic breast cancer cells to chemotherapy. J Natl Cancer Inst 100:672-679. doi:10.1093/jnci/djn123

188. Oravecz-Wilson KI, Philips ST, Yilmaz OH et al (2009) Persistence of leukemia-initiating cells in a conditional knockin model of an imatinib-responsive myeloproliferative disorder. Cancer Cell 16:137-148. doi:10.1016/j.ccr.2009.06.007

189. Chen J, Li Y, Yu T-S et al (2012) A restricted cell population propagates glioblastoma growth after chemotherapy. Nature 488:522-526. doi:10.1038/nature11287

190. Wei Y, Jiang Y, Zou F et al (2013) Activation of PI3K/Akt pathway by CD133-p85 interaction promotes tumorigenic capacity of glioma stem cells. Proc Natl Acad Sci USA 110:6829-6834. doi:10.1073/pnas.1217002110

191. Jiang X, Xing H, Kim T-M et al (2012) Numb regulates glioma stem cell fate and growth by altering epidermal growth factor receptor and Skp1-Cullin-F-box ubiquitin ligase activity. Stem Cells 30:1313-1326. doi:10.1002/stem.1120

192. Marumoto T, Tashiro A, Friedmann-Morvinski D et al (2009) Development of a novel mouse glioma model using lentiviral vectors. Nat Med 15:110-116. doi:10.1038/nm.1863

193. Friedmann-Morvinski D, Bushong EA, Ke E et al (2012) Dedifferentiation of neurons and astrocytes by oncogenes can induce gliomas in mice. Science 338:1080-1084. doi:10.1126/ science. 1226929

194. Bischoff JR, Anderson L, Zhu Y et al (1998) A homologue of Drosophila aurora kinase is oncogenic and amplified in human colorectal cancers. EMBO J 17:3052-3065. doi:10.1093/em boj/17.11.3052

195. Sen S, Zhou H, White RA (1997) A putative serine/threonine kinase encoding gene BTAK on chromosome 20q13 is amplified and overexpressed in human breast cancer cell lines. Oncogene 14:2195-2200. doi:10.1038/sj.onc.1201065

196. Tanner MM, Grenman S, Koul A et al (2000) Frequent amplification of chromosomal region 20q12-q13 in ovarian cancer. Clin Cancer Res 6:1833-1839

197. Sakakura C, Hagiwara A, Yasuoka R et al (2001) Tumouramplified kinase BTAK is amplified and overexpressed in gastric cancers with possible involvement in aneuploid formation. Br J Cancer 84:824-831. doi:10.1054/bjoc.2000.1684

198. Sen S, Zhou H, Zhang R-D et al (2002) Amplification/overexpression of a mitotic kinase gene in human bladder cancer. $\mathrm{J}$ Natl Cancer Inst 94:1320-1329

199. Li D, Zhu J, Firozi PF et al (2003) Overexpression of oncogenic STK15/BTAK/Aurora A kinase in human pancreatic cancer. Clin Cancer Res 9:991-997

200. D'Assoro AB, Liu T, Quatraro C et al (2013) The mitotic kinase Aurora-A promotes distant metastases by inducing epithelialto-mesenchymal transition in $\mathrm{ER} \alpha(+)$ breast cancer cells. Oncogene. doi:10.1038/onc.2012.628

201. Do T-V, Xiao F, Bickel LE et al (2013) Aurora kinase A mediates epithelial ovarian cancer cell migration and adhesion. Oncogene. doi:10.1038/onc.2012.632

202. Zhang H, Chen X, Liu B, Zhou L (2011) Effects of stable knockdown of Aurora kinase A on proliferation, migration, chromosomal instability, and expression of focal adhesion kinase and matrix metalloproteinase-2 in HEp-2 cells. Mol Cell Biochem 357:95-106. doi:10.1007/s11010-011-0879-1

203. Huang F-J, You W-K, Bonaldo P et al (2010) Pericyte deficiencies lead to aberrant tumor vascularizaton in the brain of the NG2 null mouse. Dev Biol 344:1035-1046. doi:10.1016/ j.ydbio.2010.06.023

204. McAvoy S, Ganapathiraju SC, Ducharme-Smith AL et al (2007) Non-random inactivation of large common fragile site genes in different cancers. Cytogenet Genome Res 118:260-269. doi: $10.1159 / 000108309$

205. Schimanski CC, Schmitz G, Kashyap A et al (2005) Reduced expression of Hugl-1, the human homologue of Drosophila tumour suppressor gene $\mathrm{lgl}$, contributes to progression of colorectal cancer. Oncogene 24:3100-3109. doi:10.1038/sj.onc. 1208520

206. Kuphal S, Wallner S, Schimanski CC et al (2006) Expression of Hugl-1 is strongly reduced in malignant melanoma. Oncogene 25:103-110. doi:10.1038/sj.onc. 1209008

207. Grifoni D, Garoia F, Schimanski C (2004) The human protein Hugl-1 substitutes for Drosophila lethal giant larvae tumour suppressor function in vivo. Oncogene 23:8688-8694. doi:10.1 038/sj.onc. 1208023

208. Lisovsky M, Dresser K, Baker S et al (2009) Cell polarity protein Lg12 is lost or aberrantly localized in gastric dysplasia and adenocarcinoma: an immunohistochemical study. Mod Pathol 22:977-984. doi:10.1038/modpathol.2009.68

209. Spaderna S, Schmalhofer O, Wahlbuhl M et al (2008) The transcriptional repressor ZEB1 promotes metastasis and loss of cell polarity in cancer. Cancer Res 68:537-544. doi:10.1158/00085472.CAN-07-5682

210. Kashyap A, Zimmerman T, Ergül N et al (2013) The human Lgl polarity gene, Hugl-2, induces MET and suppresses Snail tumorigenesis. Oncogene 32:1396-1407. doi:10.1038/onc.2012.162

211. Toda M, Iizuka Y, Yu W et al (2001) Expression of the neural RNA-binding protein Musashi1 in human gliomas. Glia 34:1-7

212. Potten CS, Booth C, Tudor GL et al (2003) Identification of a putative intestinal stem cell and early lineage marker; musashi-1. Differentiation 71:28-41 
213. Götte M, Wolf M, Staebler A et al (2008) Increased expression of the adult stem cell marker Musashi-1 in endometriosis and endometrial carcinoma. J Pathol 215:317-329. doi:10.1002/ path. 2364

214. Muto J, Imai T, Ogawa D et al (2012) RNA-binding protein Musashil modulates glioma cell growth through the post-transcriptional regulation of Notch and PI3 kinase/Akt signaling pathways. PLoS ONE 7:e33431. doi:10.1371/ journal.pone.0033431

215. Sureban SM, May R, George RJ et al (2008) Knockdown of RNA binding protein musashi-1 leads to tumor regression in vivo. Gastroenterology 134:1448-1458. doi:10.1053/j.gastro.2008.02.057

216. Westhoff B, Colaluca IN, D'Ario G et al (2009) Alterations of the Notch pathway in lung cancer. Proc Natl Acad Sci USA 106:22293-22298. doi:10.1073/pnas.0907781106

217. Nolan ME, Aranda V, Lee S et al (2008) The polarity protein Par6 induces cell proliferation and is overexpressed in breast cancer. Cancer Res 68:8201-8209. doi:10.1158/0008-5472. CAN-07-6567

218. Wolf G, Elez R, Doermer A et al (1997) Prognostic significance of polo-like kinase (PLK) expression in non-small cell lung cancer. Oncogene 14:543-549. doi:10.1038/sj.onc.1200862

219. Weichert W, Ullrich A, Schmidt M et al (2006) Expression patterns of polo-like kinase 1 in human gastric cancer. Cancer Sci 97:271-276. doi:10.1111/j.1349-7006.2006.00170.x

220. Takai N, Miyazaki T, Fujisawa K et al (2001) Expression of polo-like kinase in ovarian cancer is associated with histological grade and clinical stage. Cancer Lett 164:41-49

221. Weichert W, Schmidt M, Gekeler V et al (2004) Polo-like kinase 1 is overexpressed in prostate cancer and linked to higher tumor grades. Prostate 60:240-245. doi:10.1002/pros.20050

222. Nogawa M, Yuasa T, Kimura S et al (2005) Intravesical administration of small interfering RNA targeting PLK-1 successfully prevents the growth of bladder cancer. J Clin Invest 115:978985. doi:10.1172/JCI23043

223. Maire V, Némati F, Richardson M et al (2013) Polo-like kinase 1: a potential therapeutic option in combination with conventional chemotherapy for the management of patients with triple-negative breast cancer. Cancer Res 73:813-823. doi:10.1158/0008-5472.CAN-12-2633

224. Knecht R, Elez R, Oechler M et al (1999) Prognostic significance of polo-like kinase (PLK) expression in squamous cell carcinomas of the head and neck. Cancer Res 59:2794-2797
225. Dietzmann K, Kirches E, Von Bossanyi P et al (2001) Increased human polo-like kinase-1 expression in gliomas. J Neurooncol 53:1-11

226. Lee C, Fotovati A, Triscott J et al (2012) Polo-like kinase 1 inhibition kills glioblastoma multiforme brain tumor cells in part through loss of SOX2 and delays tumor progression in mice. Stem Cells 30:1064-1075. doi:10.1002/stem.1081

227. Regala RP, Weems C, Jamieson L et al (2005) Atypical protein kinase $\mathrm{C}$ iota is an oncogene in human non-small cell lung cancer. Cancer Res 65:8905-8911

228. Kojima Y, Akimoto K, Nagashima Y et al (2008) The overexpression and altered localization of the atypical protein kinase $\mathrm{C}$ lambda/iota in breast cancer correlates with the pathologic type of these tumors. Human Pathol 39:824-831. doi:10.1016/j.humpath.2007.11.001

229. Eder AM, Sui X, Rosen DG et al (2005) Atypical PKCiota contributes to poor prognosis through loss of apical-basal polarity and cyclin E overexpression in ovarian cancer. Proc Natl Acad Sci USA 102:12519-12524. doi:10.1073/pnas.0505641102

230. Ishiguro H, Akimoto K, Nagashima $Y$ et al (2009) aPKClambda/iota promotes growth of prostate cancer cells in an autocrine manner through transcriptional activation of interleukin-6. Proc Natl Acad Sci USA 106:16369-16374. doi:10.1073/ pnas.0907044106

231. Regala RP, Weems C, Jamieson L et al (2005) Atypical protein kinase Ciota plays a critical role in human lung cancer cell growth and tumorigenicity. J Biol Chem 280:31109-31115. doi:10.1074/jbc.M505402200

232. Geevimaan K, Babu P (2013) Deregulation of cell polarity proteins in gliomagenesis. Evol Mol Biol Brain Tumors Ther Implic. doi: $10.5772 / 52365$

233. Zhan L, Rosenberg A, Bergami KC et al (2008) Deregulation of scribble promotes mammary tumorigenesis and reveals a role for cell polarity in carcinoma. Cell 135:865-878. doi:10.1016/j. cell.2008.09.045

234. Boulay J-L, Stiefel U, Taylor E et al (2009) Loss of heterozygosity of TRIM3 in malignant gliomas. BMC Cancer 9:71 doi:10.1186/1471-2407-9-71

235. Liu Y, Raheja R, Yeh N, et al (2013) TRIM3, a tumor suppressor linked to regulation of $\mathrm{p} 21$ (Waf1/Cip1). Oncogene. doi:10.1038 lonc.2012.596 